\title{
RHEOLOGICAL STUDY OF A NOVEL SULFOBETAINE SURFACTANT-BASED ACID SYSTEM
}

\author{
A Thesis \\ by \\ SEMA CETIN
}
Submitted to the Office of Graduate and Professional Studies of Texas A\&M University in partial fulfillment of the requirements for the degree of MASTER OF SCIENCE

\begin{abstract}
Chair of Committee, Hisham A. Nasr-El-Din
Committee Members, Maria Barrufet Mahmoud El-Halwagi

Head of Department, A. Daniel Hill
\end{abstract}

December 2015

Major Subject: Petroleum Engineering

Copyright 2015 Sema Cetin 


\section{ABSTRACT}

Acid stimulation is a widely used well treatment technique applied to enhance oil production by creating conductive channels through the formation, resulting an improved flow property. Viscoelastic surfactant (VES)-based acids have been employed for acidizing jobs due to their ability to build up sufficient viscosity for acid diversion and fluid loss reduction, and to break into low viscosity after the treatment is completed. This work studied rheological properties of a new zwitterionic viscoelastic surfactant-based stimulation fluid. Impacts of many variables on the rheological characteristics of the VES-based live and spent acids were examined.

Rheological experiments were conducted using a high pressure/high temperature (HPHT) viscometer. Viscosity measurements were performed between the temperatures of 78 to $350^{\circ} \mathrm{F}$ and shear rates of 10 to $935 \mathrm{~s}^{-1}$ at 300 psi. Examined acid additives included: corrosion inhibitor, formic acid, methanol, demulsifier, $\mathrm{H}_{2} \mathrm{~S}$ scavenger, iron control agents, and mutual solvent. As a contaminant, the effect of Fe(III) was investigated. In addition, the impacts of surfactant concentration, salt type and salt concentration on the viscosity of the VES-based acid systems were tested.

Experimental results indicated that the new VES-based acid system exhibits a sufficient viscosity for acid diversion at temperatures up to $270^{\circ} \mathrm{F}$. Contrary to spent acid blends, VES did not build up high viscosity in live acid. Apparent viscosity of the spent acid showed a strong relation with surfactant concentration, salt type and salt concentration. Corrosion inhibitor concentration above 0.5 vol\% caused a notable loss in the viscosity as the temperature increased gradually. Dependency on methanol was strong enough that it resulted in a decline of the apparent viscosity of both live and spent acid solutions. Iron control agents (citric acid and EDTA) 
did not alter the viscous behavior notably. $\mathrm{H}_{2} \mathrm{~S}$ scavenger showed a similar effect as iron control agents, while demulsifier and mutual solvent caused a reduction in the apparent viscosity. Fe(III) contamination caused fluctuations in the live acid viscosity due to generated VES-iron complex. In spent condition, this complex caused phase separation that resulted in loss of viscosity.

This study showed that the new VES-based acid has the ability to build and maintain sufficient viscosity at higher temperatures than the currently used VES types. The acid system yielded higher tolerance to corrosion inhibitor than many other VES-based acids, and showed compatibility with a wide range of salt types. On the basis of the results obtained, optimum conditions to achieve the desired rheological profile for a successful well stimulation operation are presented. 


\section{DEDICATION}

To my beloved husband,

who has been a constant source of motivation, encouragement and inspiration

and to my family,

my mother, my father and my sister who have always loved and supported me unconditionally. 


\section{ACKNOWLEDGEMENTS}

I would like to express my sincere gratitude to my advisor, Dr. Hisham A. NasrEl-Din, for his continues support and guidance throughout this study. I am thankful to him for his time, effort and for giving me the opportunity to be a part of this project.

I would like to acknowledge Dr. Maria Barrufet and Dr. Mahmoud El-Halwagi who graciously agreed to serve on my committee.

I am truly thankful to the Turkish Petroleum Corporation for their financial assistance.

Thanks to my friends who became a family to me in College Station for making this journey a great experience and full of invaluable memories.

Finally, I would like to thank my family for their continues support and encouragement. 


\section{TABLE OF CONTENTS}

Page

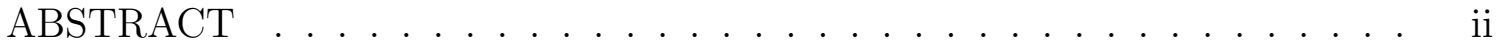

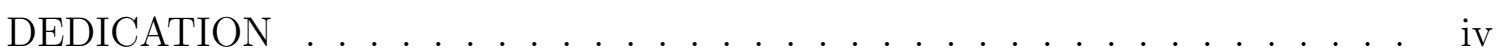

ACKNOWLEDGEMENTS . . . . . . . . . . . . . . . v

TABLE OF CONTENTS ............................ vi

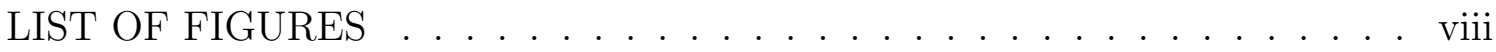

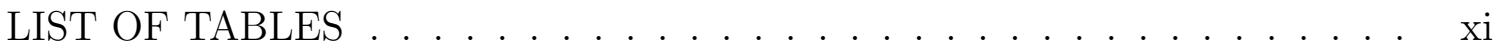

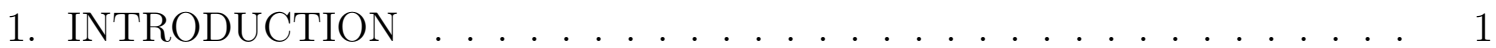

1.1 Acid Stimulation . . . . . . . . . . . . . . . . . . . . 1

1.1.1 Matrix Acidizing of Carbonate Rocks . . . . . . . . . . . 2

1.1.2 Acid Fracturing of Carbonate Reservoirs . . . . . . . . . . . . 2

1.1.3 Leak-Off Control and Acid Diversion . . . . . . . . . . . . 3

1.2 Acid Additives . . . . . . . . . . . . . . . . . . 6

1.3 Viscoelastic Surfactants . . . . . . . . . . . . . . . . 7

1.3.1 Surfactant Classification . . . . . . . . . . . . . 9 9

1.4 Objectives ............................ 11

2. MATERIALS AND EXPERIMENTAL STUDIES . . . . . . . . . . . . . 12

2.1 Materials . . . . . . . . . . . . . . . . . . . . 12

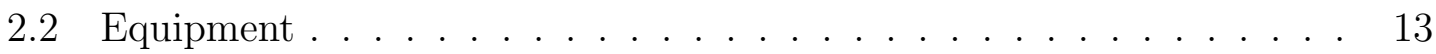

2.3 Methods . . . . . . . . . . . . . . . . . . . . 14

2.3.1 Sample Preparation . . . . . . . . . . . . . . . 14

2.3.2 Rheological Tests . . . . . . . . . . . . . . . 15

3. RESULTS AND DISCUSSION . . . . . . . . . . . . . . . . . 17

3.1 Effect of Surfactant Concentration on Apparent Viscosity . . . . . . . 17

3.2 Effect of Temperature on Apparent Viscosity . . . . . . . . . . . . . . 18

3.3 Effect of Salt Type and Concentration on the Apparent Viscosity . . 19

3.3.1 Effect of $\mathrm{CaCl}_{2}$ Concentration . . . . . . . . . . . . 19 
3.3.2 Effect of Salt Type . . . . . . . . . . . . . . . . . . . . . . 22

3.4 Apparent Viscosity of Live Acids . . . . . . . . . . . . . . . . . 23

3.4.1 Effect of Corrosion Inhibitor Concentration . . . . . . . . . . 23

3.4 .2 Effect of Methanol . . . . . . . . . . . . . . . . 24

3.4.3 Effect of Iron Contamination . . . . . . . . . . . . . . . . 26

3.5 Apparent Viscosity of Spent Acids . . . . . . . . . . . . . 28

3.5.1 Effect of Corrosion Inhibitor Concentration . . . . . . . . . . 29

3.5.2 Effect of Methanol . . . . . . . . . . . . . . . . . . 31

3.5.3 Effect of Mutual Solvent . . . . . . . . . . . . . . . 33

3.5.4 Effect of $\mathrm{H}_{2} \mathrm{~S}$ Scavenger and Demulsifier . . . . . . . . . 35

3.5.5 Effect of Iron Contamination . . . . . . . . . . . . . . . . 38

3.5.6 Effect of Iron Control Agents _. . . . . . . . . . . . 40

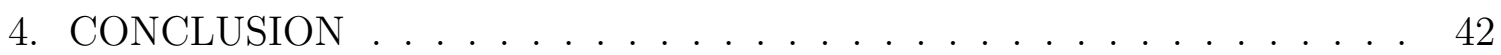

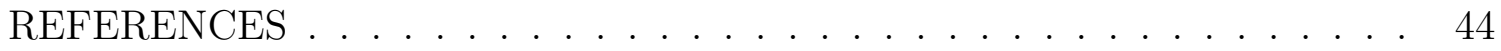




\section{LIST OF FIGURES}

FIGURE

Page

1.1 Chemical diversion with VES-based stimulation fluid (Zana and Kaler

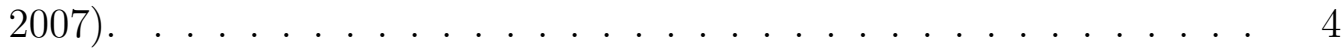

1.2 Synthesis of betaines (Porter 1991). . . . . . . . . . . . . 11

2.1 Structure of VES-A (Gadberry et al. 2014). . . . . . . . . . . 12

3.1 Effect of VES concentration and temperature on the on the apparent viscosity of spent acid. . . . . . . . . . . . . . . 18

3.2 Temperature limitation on the apparent viscosity of VES-A based spent acid. . . . . . . . . . . . . . . . . . . .

3.3 Alteration of rod-like micelle structure upon increased salt concentration (Candau et al. 1993). . . . . . . . . . . . . . . . . . 20

3.4 Apparent viscosity as a function of temperature for spent acids containing various concentrations of $\mathrm{CaCl}_{2} \ldots \ldots \ldots \ldots$

3.5 Apparent viscosity as a function of shear rate for spent acids containing various concentrations of $\mathrm{CaCl}_{2} \ldots \ldots \ldots \ldots \ldots$

3.6 Effect of cation type on the apparent viscosity as a function of temperature. . . . . . . . . . . . . . . . . 22

3.7 Effect of temperature on the apparent viscosity of live acid systems including 6 vol\% VES A and various concentrations of corrosion in-

3.8 Shear history dependence of the apparent viscosity of live acid systems including 6 vol\% VES A and various concentrations of corrosion inhibitor. . . . . . . . . . . . . . . . . . 2

3.9 Effect of methanol concentration and temperature on the viscosity of live acids containing 6 vol\% VES A and 0.5 vol\% corrosion inhibitor. 
3.10 Shear history dependence of live acid systems containing 6 vol\% VES A, 0.5 vol\% corrosion inhibitor and various concentrations of methanol. 25

3.11 Apparent viscosity as a function of temperature for live acid with iron

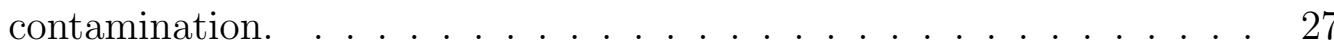

3.12 Apparent viscosity as a function of shear rate for live acid with iron

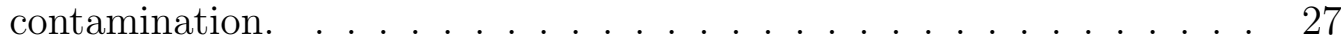

3.13 Effect of temperature on the apparent viscosity of spent acid systems including 6 vol\% VES A and various concentrations of corrosion inhibitor. . . . . . . . . . . . . . . .

3.14 Shear history dependence of the apparent viscosity of spent acid systems including 6 vol\% VES A and various concentrations of corrosion inhibitor. . . . . . . . . . . . . . . . . . 30

3.15 Effect of increased formic acid concentration on the apparent viscosity of spent acid as a function of temperature. . . . . . . . . . 30

3.16 Effect of methanol concentration and temperature on the viscosity of spent acid. . . . . . . . . . . . . . . . . 32

3.17 Shear history dependence of spent acid systems containing methanol. 32

3.18 Chemical structure of ethylene glycol monobutyl ether. . . . . . . . . 33

3.19 Apparent viscosity of spent acid in the presence of mutual solvent. . . 34

3.20 Shear history dependency of spent acid including mutual solvent. . . 34

3.21 Effect of $\mathrm{H}_{2} \mathrm{~S}$ scavenger on apparent viscosity of spent acid as a func-

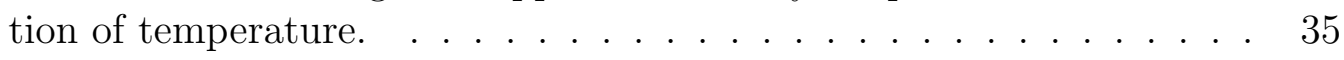

3.22 Effect of demulsifier on apparent viscosity of spent acid as a function

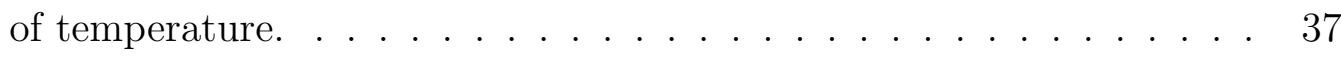

3.23 Effect of additives on apparent viscosity of spent acid as a function of shear rate. . . . . . . . . . . . . . . . 37

3.24 Spent acid samples with iron contamination. . . . . . . . . . . 38

3.25 Effect of $\mathrm{Fe}(\mathrm{III})$ contamination on viscosity of spent acid as a function

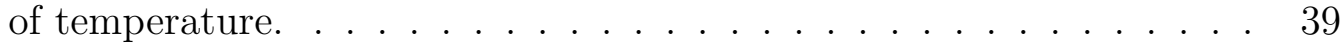


3.26 Effect of $\mathrm{Fe}(\mathrm{III})$ contamination on viscosity of spent acid as a function of shear rate. . . . . . . . . . . . . . . . . . . 39

3.27 Chemical structure of ethylenedinitrilo tetraacedic acid disodium salt. 40

3.28 Chemical structure of citric acid. . . . . . . . . . . . . . 40

3.29 Effect of iron control agents on viscosity of spent acid as a function of

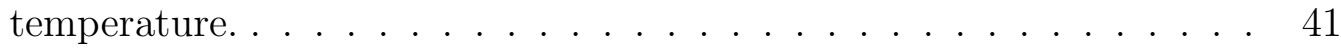

3.30 Effect of iron control agents on viscosity of spent acid as a function of shear rate. . . . . . . . . . . . . . . . . . . . . . . 44 41 


\section{LIST OF TABLES}

TABLE

1.1 Acid diversion mechanisms used in well stimulation. . . . . . . . . . 5

1.2 Polymer and VES-based diversion systems comparison. . . . . . . . 6

2.1 Main components of the acid additives examined. . . . . . . . . . 13

2.2 Concentrations of additives examined. . . . . . . . . . . . . 15

3.1 Composition of corrosion inhibitor tested. . . . . . . . . . . . 31

3.2 Composition of $\mathrm{H}_{2} \mathrm{~S}$ scavenger tested. . . . . . . . . . . . . . . . . . . 35

3.3 Composition of demulsifier tested. . . . . . . . . . . . . . 36 


\section{INTRODUCTION}

\subsection{Acid Stimulation}

Low permeability causes low flow rate of hydrocarbons toward the wellbore. On the other hand, formation damage impairs reservoir and acts as a barrier that causes flow restrictions. Some examples of many possible causes of formation damage include fines migration, emulsions, paraffin and asphaltenes, water swellable clays, mineral precipitation. Several stimulation techniques are applied to reservoirs to overcome these problems. Acid stimulation is one of the techniques used to enhance productivity.

Acidizing is one of the oldest well stimulation techniques still in use today. The first acidizing application dates back to 1895. The Standard Oil Company injected concentrated hydrochloric acid $(\mathrm{HCl})$ to oil wells producing from carbonate formation

with an extraordinary achievement in Lima, Ohio. However, the effectiveness of the technique was limited until the development of corrosion inhibitors (Kalfayan 2008). With the advent of effective corrosion inhibitors, acid treatment of oil and gas wells prospered further to the development of acidizing continued from past to today, leading to the establishment of the service industry. This relatively simple and significantly cost-effective application is able to enhance well productivity and hydrocarbon recovery today.

Two techniques used to stimulate production are:

1. Matrix acidizing

2. Acid fracturing

Both sandstone and carbonate formations can be stimulated by acidizing tech- 
niques. This study focused on carbonate acidizing. The most common acid used in the field for carbonate acidizing is hydrochloric acid $(\mathrm{HCl})$ at concentrations varying from 15 to $28 \mathrm{wt} \%$. Lower concentrations of acids are also used for well cleanup purposes. The main reactions of interest in the carbonate acid stimulation are dissolution of limestone $\left(\mathrm{CaCO}_{3}\right)$ and dolomite $\left(\mathrm{CaMg}\left(\mathrm{CO}_{3}\right)_{2}\right)$ by $\mathrm{HCl}$ as follow:

$\mathrm{CaCO}_{3}+2 \mathrm{H}_{3} \mathrm{O}^{+} \rightleftharpoons \mathrm{Ca}^{2+}+\mathrm{CO}_{2}$

and

$\mathrm{CaMg}\left(\mathrm{CO}_{3}\right)_{2}+4 \mathrm{H}_{3} \mathrm{O}^{+} \rightleftharpoons \mathrm{Ca}^{2+}+\mathrm{Mg}^{2+}+2 \mathrm{CO}_{2}+6 \mathrm{H}_{2} \mathrm{O}$.

\subsubsection{Matrix Acidizing of Carbonate Rocks}

Acid mixture is injected into the reservoir below fracturing pressure to dissolve solids ensconced in pore spaces, pore throats and pore walls. Matrix acidizing is performed to remove or bypass the damaged zone in the formation by either enlarging the existing flow paths or forming new alternative conductive channels, which are known as wormholes, through the formation rock (Coulter and Jennings 1999). However, once the wormholes are created, acid has a tendency to flow through the same wormholes rather than other portions of the formation intended to be treated. Diversion techniques are used for an effective coverage. These techniques are used to form a transitory blockage in the initially made wormhole so that later injected acid can be directed to untreated zones.

\subsubsection{Acid Fracturing of Carbonate Reservoirs}

Acid fracturing is a hydraulic fracturing technique applied to low-permeability and acid-soluble rocks, such as $\left(\mathrm{CaCO}_{3}\right)$ and dolomite $\left(\mathrm{CaMg}\left(\mathrm{CO}_{3}\right)_{2}\right)$. Acid is in- 
jected into the formation above the fracture pressure to create highly conductive channels or reopen the natural fractures. The acid reacts with the fracture walls by creating certain geometric patterns to keep these conductive channels open after the external pressure is relieved (Lo and Dean 1989, Nierode et al. 1972). Effectiveness of the treatment depends on the conductivity and length of the fracture. Fluid loss impacts both fracture length and conductivity simultaneously (Renpu 2011).

\subsubsection{Leak-Off Control and Acid Diversion}

As the stimulation fluid is injected into the well, it starts reacting with the first rock it contacts or with the most reactive rock. Furthermore, acid continuously erodes the carbonate surface while flowing through, making it difficult for other liquids to build a filter cake that works as a fluid loss barrier. Another problem is that acid follows the least resistant path and selectively reacts with the formation to create wormholes perpendicular to the fracture face. Crowe et al. (1989) indicated that acid tends to flow through these perpendicular wormholes rather than lengthening the fracture, which increases the fluid loss and results in reduction of hydraulic pressure in the well.

An effective stimulation job requires proper acid placement into the target zones (Gallus and Pye 1972). This practice can be difficult due to reservoir heterogeneity, unevenly situated damage or the depth of the targeted section. Placement of the acid uniformly and improve its contact with the targeted interval continues acid diversion during the treatment is critical. Mechanical and chemical techniques are available to control and minimize the acid leak-off by creating a temporary blockage in the wormholes.

Acid diversion techniques used in matrix acidizing can be also applied for fluid loss control in acid fracturing. These techniques can be divided into two categories: 
mechanical and chemical (Table 1.1). Ball sealers, packer systems and coiled tubing methods are used to provide mechanical diversion, but the effectiveness of these methods are limited in openhole applications (Kalfayan 2008). As for chemical diversion, increasing the viscosity of the fluid help acid to be diverted into lower permeability zones by creating a temporary blockage in the wormholes. Fig. 1.1 illustrates the chemical diversion mechanism. These methods can be utilized in both cased and openhole wells. Polymers and surfactants are most commonly used chemicals as viscosifying agents.

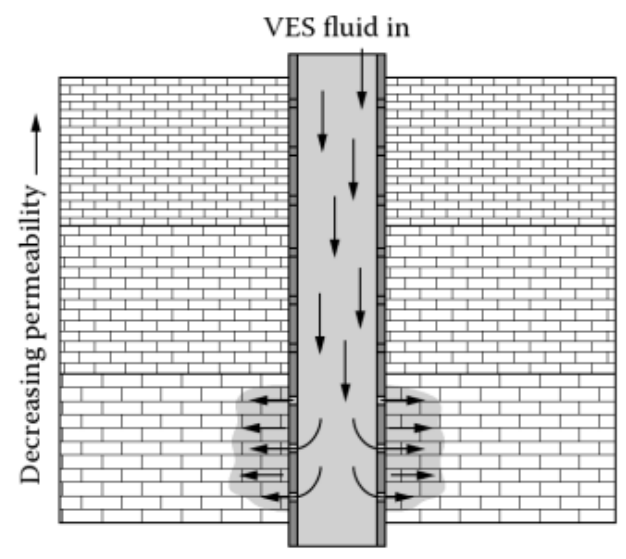

(a)

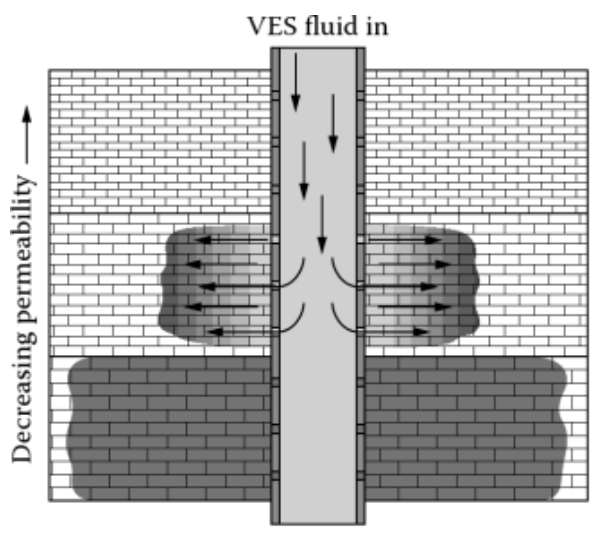

(b)

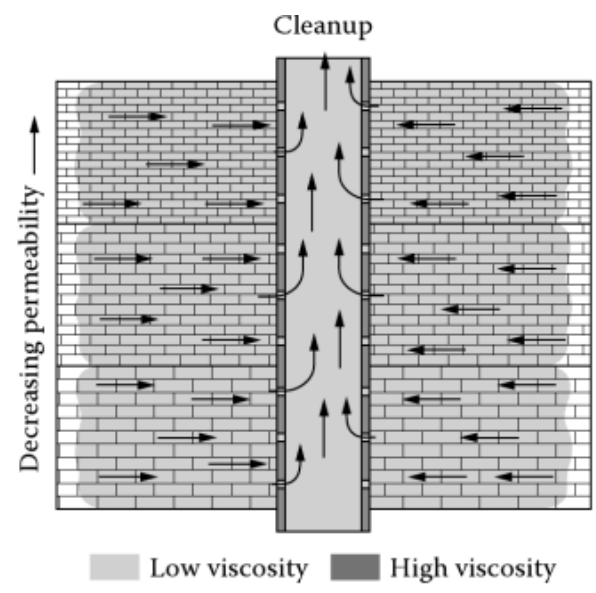

(c)

Figure 1.1: Chemical diversion with VES-based stimulation fluid (Zana and Kaler 2007). 


\begin{tabular}{|c|c|}
\hline \multicolumn{2}{|c|}{ Methods for Acid Diversion } \\
\hline Mechanical Diversion & Chemical Diversion \\
\hline Ball sealers & Degradable particulates \\
\hline Packers & Foam \\
\hline Coiled tubing & Emulsifying agents \\
\hline Bull-heading & $\begin{array}{ll}\text { Gelling agents } & \text { a. Polymer-based gelled acids } \\
\text { b. Surfactant-based gelled acids }\end{array}$ \\
\hline
\end{tabular}

Table 1.1: Acid diversion mechanisms used in well stimulation.

Polymers added to the acid solution can be crosslinked by chemical covalent bonds either on the surface (Johnson et al. 1988) or in the formation which is called in-situgelled acid (Yeager and Shuchart 1997) by forming a permanent three-dimensional polymer network. These crosslinked polymer-based acid systems consist of HCl, polymer, cross linker, buffer and other required substances. $\mathrm{pH}$ is the control mechanism for in-situ gelation. As the acid is spent, $\mathrm{pH}$ values increases. The crosslinker does not react with polymer until the $\mathrm{pH}$ reaches around 2 . When $\mathrm{pH}$ reaches 4 , breaker becomes active and dissociates the gelled fluid decreasing the viscosity for an easy flow back. Despite the extensive use of polymer-based acids, there are several drawbacks associated with crosslinked polymer-based acids. Precipitation of crosslinker Fe(III) in tight carbonate rocks at high temperature is one of the concerns (Lynn and Nasr-El-Din 2001). Permeability damage also occurs due to polymer retention in the formation (Taylor and Nasr-El-Din 2002). Nasr-El-Din et al. (2002) observed that hydrogen sulfide scavengers loose ability to remove hydrogen sulfide as a consequence of polymer interaction.

In an effort to minimize polymer-induced drawbacks, viscoelastic surfactant-based acids were presented to the industry as an alternative self diverting fluid (Chang et al. 2001). Contrary to polymer-based acids, viscoelastic surfactant-based fluids 
are easy to prepare in the field due to requirement of less number of additives. These acid systems do not leave any residue after breakdown and do not require metallic crosslinkers. Surfactants reduce the frictional pressure loss in the coiled tubing. Viscoelastic surfactant-based acid systems were effectively utilized in both matrix acidizing (Al-Mutawa et al. 2005, Lungwitz et al. 2007, Nasr-El-Din et al. 2006) and acid fracturing (Al-Muhareb et al. 2003, Nasr-El-Din et al. 2003) jobs.

\begin{tabular}{cl}
\hline \multirow{2}{*}{$\begin{array}{c}\text { Polymer-based } \\
\text { acid diversion }\end{array}$} & $\begin{array}{l}\text { Reduces the permeability due to polymer retention } \\
\text { Large volume of fluid is required } \\
\text { Unfavorably interacts with H2S scavenger }\end{array}$ \\
\hline \hline & Less number of additives is required \\
& Simple to prepare and place with coiled tubing or bullheading \\
& Easy to break with hydrocarbon contact and water injection \\
VES-based & Reduced friction loss in coiled tubing \\
acid diversion & Less volume of fluid is required \\
& Easy to clean up, does not leave residue \\
& Adversely affected by ferric iron \\
\hline
\end{tabular}

Table 1.2: Polymer and VES-based diversion systems comparison.

\subsection{Acid Additives}

Fluids injected into carbonate reservoirs are based on $\mathrm{HCl}$ or organic acids with a purpose to enhance the productivity of the well by removing the damage or stimulating the wellbore area. With an objective to avoid a secondary damage due to precipitation of undesired byproducts on matrix or equipment, various additives are included in the acid systems with different functions such as $\mathrm{pH}$ adjustment, bacteria control, equipment protection, temperature stability improvement, and such. Mainly, corrosion inhibitor, $\mathrm{H}_{2} \mathrm{~S}$ scavenger, iron control agents, breakers and surfactants are 
the additives used in acid blends (Kalfayan 2008).

Since $\mathrm{HCl}$ is a strong acid, compatible corrosion inhibitors are always necessary to minimize the corrosion of tubular. Iron control agents minimize the formation damage caused as a result of iron precipitation. Iron control agents react with dissolved iron and other metal ions inhibiting the precipitation by improving their solubility. Non-ionic surfactants are used in the acid mixture to aid acid clean up as well as to improve oil and gas flow by leaving the formation water-wet. Mutual solvents are used to improve the solubility of additives such as corrosion inhibitors, and reduce the adsorption of dissolved material by matrix. Non-emulsifying agents are also added to avoid acid-oil emulsification.

\subsection{Viscoelastic Surfactants}

Viscoelastic surfactants (VES) were first introduced by Dow Chemical Company in 1984 (Evani 1984). This family of surfactants was used as thickening agents in many products such as liquid detergents and cosmetics, and adopted soon by the oil and gas industry. VES started to be used in gravel-pack applications, and a new VES-based hydraulic fracturing fluid was introduced as an alternative to polymerbased fracturing fluids (Card et al. 1999, Samuel et al. 1997). Based on the success of hydraulic fracturing and gavel packing fluids, this technology has evolved and been extended to applications including fracturing, completion, acidizing and water shut-off.

Viscoelastic surfactants contain both a hydrophilic part and a hydrophobic part, which are covalently connected to each other. The hydrophilic part is referred as the polar head group which tends to be in contact with water, and the water-repelling hydrophobic tail is generally a hydrocarbon chain (alkyl or alkylaryl). When a surfactant is absorbed by a hydrophobic surface, the tail stays in contact with the 
surface, exposing the hydrophilic head group to the aqueous solution. As a result, the surface can be transformed into a hydrophilic character, and interfacial tension between the surface and water can be reduced.

Micelle formation, self-aggregation of surfactant molecules into supramolecular structures, is another mechanism that takes place. The driving force in this selfassembling process is the elimination of the contact between water and hydrophobic tail. Micelle generation can start at certain surfactant concentrations called critical micelle concentration (CMC) (Hoffmann et al. 1992, Israelachvili 2011). Critical micelle concentration is determined by two opposing forces between the surfactant molecules; the repulsive forces between the polar head groups and the attractive forces between the hydrophobic tail groups. As the concentration of the surfactant increases, the distance between the tail groups decrease strengthening the attraction. As well as self-aggregation, adsorption of surfactants also relies on the concentration.

The structure of the micelles depends on the charge, geometry, concentration and ionic strength of the surfactant, as well as the physical conditions such as temperature, salt concentration and shear rate (Cates and Candau 1990). The geometry of the micelle can be described based on its dimensionless packing parameter, $\mathrm{P}$ (Israelachvili and Mitchell 1975).

$P=V_{o} / a l_{o}$

where $\mathrm{V}_{o}$ is the volume, $l_{o}$ is the length and $a$ is the surface area of the surfactant molecule. The connection between the packing parameter and the micelle geometry is: $0<\mathrm{V}_{o} / \mathrm{al}_{o}<1 / 3$ for spherical micelle, $1 / 3<\mathrm{V}_{o} / \mathrm{al}_{o}<1 / 2$ for cylindrical micelle and $1 / 2<\mathrm{V}_{o} / \mathrm{al}_{o}<1$ for bilayer and vesicle micelle.

The simplest micelle structure is "spherical", of which the inner core is composed 
of hydrophobic tail assemblage, and hydrophilic head groups surround this core isolating it from aqueous fluid. Another form of micelle is "rod-like" or "worm-like". In this case, surfactant molecules compose a uniform three-dimensional cylindrical structure with hemispherical ends, which can become long enough to entangle with one other. Entanglement of rod-like micelles increases both the apparent viscosity and elastic properties of the fluid (Card et al. 1999, Lequeux 1996).

As the $\mathrm{HCl}$ reacts with carbonate rock, both the $\mathrm{pH}$ value of the medium and the concentration of divalent cations $\left(\mathrm{Ca}^{2+}\right.$ and $\left.\mathrm{Mg}^{2+}\right)$ increase. These chemical changes in the spent acid trigger rod-like micelle generation that results in a viscosity buildup owing to entanglement. To accomplish an optimal gel removal after the treatment, viscosity of the treatment fluid should be reduced. To break the viscosity of gelled fluid, rod-like micelles should be converted to spherical micelles. Further increase of the $\mathrm{pH}$ value as the acid reaction proceeds, or reduction of salt and/or surfactant concentration with water injection, leads to a viscosity reduction. Dissociation of entanglement can also be achieved upon exposure to hydrocarbons or other formation fluids. Internal breakers or external breakers (mutual solvent) can be used if necessary(Crews 2005, Nelson et al. 2005).

\subsubsection{Surfactant Classification}

On the basis of the charge of their hydrophilic head group, surfactants are classified into four different categories: anionic, cationic, non-ionic and amphoteric surfactants (Porter 1991).

- Anionic surfactants have a negatively charged hydrophilic head group. This class of surfactants can be carboxylates, sulfonates, sulphates and phosphates.

- Cationic surfactants carry positively charged water-soluble head groups. Cationic surfactants are mostly based on amine or quaternary ammonium groups. 
- Non-ionic surfactants have both water-soluble and oil-soluble parts, but this class of surfactants does not ionize. The hydrophilic head is commonly polyethylene oxide or polypropylene oxide.

- Amphoteric surfactants carry a positively charged, negatively charged or uncharged water-soluble part. The charge of the functional group is determined by the $\mathrm{pH}$ of the solution. Amphoteric surfactants can be synthetic, such as betaines and sulfobetaines, or can be natural such as amonioacids and phospholipids.

\section{Zwitterionic Surfactants}

Zwitterions are often referred as amphoterics; however, it is not always correct to accept these words as synonyms. Amphoteric surfactants can be anionic, cationic or zwitterionic depending on the $\mathrm{pH}$ value of medium. Only in a certain range of $\mathrm{pH}$, typically in a slightly acidic environment, do amphoteric surfactants have both positively and negatively charged head; however zwitterionic surfactants always have a cationic part, regardless of $\mathrm{pH}$, and also have an anionic part in the alkaline

pH range (Dahayanake et al. 2002, Holmberg et al. 2003). This characteristic of zwitterionic surfactants leads to large dipole moments. Unlike ionic surfactants, zwitterionics are soluble in water at a wide range of concentration, $\mathrm{pH}$ and salinity.

\section{Sulfobetaines}

Betaines are produced as a result of chloracetic acid and a tertiary amine reaction. A quaternary $\mathrm{N}$ atom and ionized $\mathrm{COO}^{-}$group is formed by this reaction (Fig.1.2). Sulfobetaines are formed when the $\mathrm{COOH}$ group is replaced with $\mathrm{SO}_{3}$. Zwitterionic sulfobetaine surfactants are used in many applications due to their tolerance to extreme conditions such as hard water, wide $\mathrm{pH}$ range and strong electrolytes. 


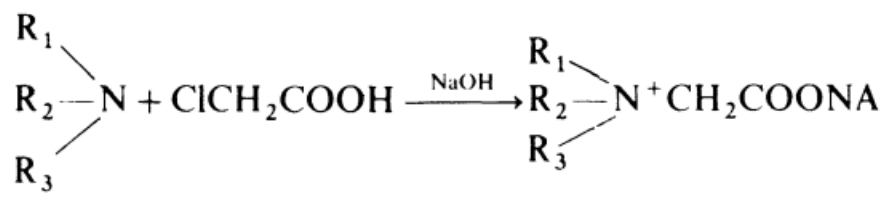

Figure 1.2: Synthesis of betaines (Porter 1991).

\subsection{Objectives}

Viscoelastic surfactant (VES) usage is becoming more and more widespread for many applications in the petroleum industry. Viscoelastic surfactants serve as fluid diversion and fluid loss control agents in well stimulation treatments. Viscoelastic surfactants have the ability to form worm-like micelles that can entangle and bulid up sufficient viscosity for targeted application. The problem with the conventional VES-based acids is not being resistant to high temperatures. In addition, micelle formation is a complex function of physical conditions of the solution and viscosity is highly dependent on the chemicals included in the acid formula.

A new sulfobetaine type of viscoelastic surfactant was studied through this work. The objective of this study is to examine the effects of temperature, shear rate, common acid additives, salinity and iron contamination on the rheological properties of this new zwitterionic type of viscoelastic surfactant. 


\section{MATERIALS AND EXPERIMENTAL STUDIES}

\subsection{Materials}

The zwitterionic surfactant (referred as VES-A) used in this study was erucamidopropyl hydroxypropyl sulfobetaine, provided by Akzo Nobel Chemicals. Gadberry et al. (2014) presents the detailed description of the invention. General chemical structure of erucamidopropyl hydroxypropyl sulfobetaine is showed in Fig. 2.1. $\mathrm{R}^{1}$ is a hydrocarbon group, $\mathrm{R}^{2}$ and $\mathrm{R}^{3}$ are alkyl or hydroxyalkyl groups, and $\mathrm{R}^{4}$ is $\mathrm{H}$, $\mathrm{OH}$, alkyl or hydroxyalkyl groups. $\mathrm{k}$ and $\mathrm{m}$ are integers from 1 to 20 .

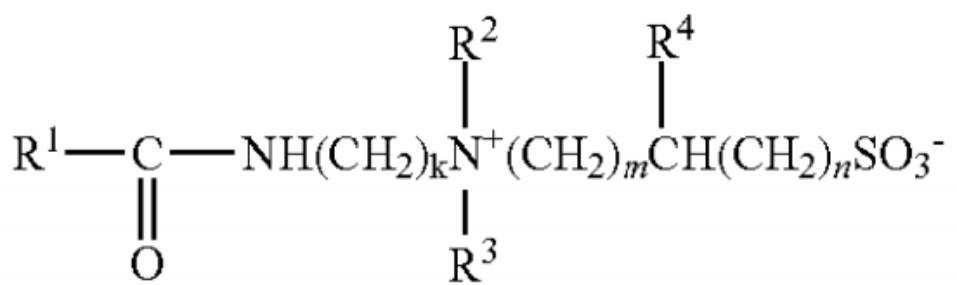

Figure 2.1: Structure of VES-A (Gadberry et al. 2014).

Solutions were prepared with ACS reagent grade $36.8 \mathrm{wt} \%$ hydrochloric acid and deionized water with a resistivity of $18.2 \mathrm{M} \Omega . \mathrm{cm}$. Acid additives used for tests were: corrosion inhibitor, formic acid, methanol, mutual solvent, citric acid, EDTA, $\mathrm{H}_{2} \mathrm{~S}$ scavenger and $\mathrm{FeCl}_{3}$ (ferric chloride) as a source of $\mathrm{Fe}^{3+}$. The salts used in the study were $\mathrm{CaCl}_{2}, \mathrm{MgCl}_{2}, \mathrm{NaCl}$, and $\mathrm{KCl}$. Compositions of the chemicals used are listed in Table 2.1. 


\begin{tabular}{lcc}
\hline Additive & Components & $\begin{array}{c}\text { Concentration } \\
(\mathbf{w t} \%)\end{array}$ \\
\hline \hline \multirow{2}{*}{ VES-A } & Surfactant & $40-60$ \\
& Organic salt & $1-3$ \\
& Ethanol & $10-22$ \\
& Propylene glycol & $10-22$ \\
& Water & $12-20$ \\
Corrosion inhibitor & Sodium chloride & $4-6$ \\
\hline Formic acid & Formic acid & $10-20$ \\
\hline Methanol & Isopropanol & $5-10$ \\
\hline Mutual solvent & Dimethylformamide & $5-10$ \\
\hline Iron control agent & Sodium iodide & $1-5$ \\
\hline Iron control agent & Formic acid & $>99$ \\
\hline \multirow{2}{*}{ Dethylenedinitrilo-tetraacetic acid } & $>99$ \\
\hline \multirow{2}{*}{$\mathrm{H}_{2}$ S scavenger } & Methyl alcohol & $>90-100$ \\
\hline & 2-Butoxyethanol & $>99$ \\
\hline
\end{tabular}

Table 2.1: Main components of the acid additives examined.

\subsection{Equipment}

A rotational, high pressure-high temperature (HPHT) rheometer (Grace Instrument, Model 5600) was used to measure the apparent viscosity of the live and spent acids. The viscometer allows work under conditions up to $1,000 \mathrm{psi}$ and $500^{\circ} \mathrm{F}$. The shear rate range is 0.00004 to $1,870 \mathrm{sec}^{-1}$. Shear stress capacity of the viscometer is up to $15,000 \mathrm{dyne} / \mathrm{cm}^{2}$. Torque value is between $14 \mu \mathrm{N} . \mathrm{m}$ to $100 \mathrm{mN}$.m. The wetted 
parts of the equipment are a Hastelloy-C276 construction, a corrosion resistant alloy. For an accurate measurement, the initial stress of the viscometer has to be between -10 and $+10 \mathrm{dyn} / \mathrm{cm}^{2}$. Bob/cup set of B5, which requires $52 \mathrm{ml}$ of sample, was used in this work.

\subsection{Methods}

\subsubsection{Sample Preparation}

Two different fluid systems were examined in this study: live acid and spent acid. For both systems, 6 vol\% VES-A and 0.5 vol\% corrosion inhibitor were used. This VES concentration was decided after conducting viscosity measurements of acid mixtures including VES concentrations of 2 to 8 vol\%. To determine the corrosion inhibitor concentration, producer company recommendations and viscosity test results were taken into consideration. Required acid additives depending on the nature of the experiment were also added to the solution at various concentrations keeping the final acid concentration at constant. $52 \mathrm{ml}$ of solution was prepared at a time. Concentrations of additives used in the acid solutions are shown in Table 2.2. These values were determined considering the typical concentrations used in field applications.

\section{Live Acid}

After calculating the required amounts of each component depending on the desired acid additive concentration, deinozed water was mixed with 0.5 vol\% corrosion inhibitor and $\mathrm{HCl}$ in a beaker, keeping the final $\mathrm{HCl}$ concentration at $15 \mathrm{wt} \%$. VESA was added to the solution following other additives. The blend was continuously mixed with a magnetic stirrer at a high rate for 15 minutes.

\section{Spent Acid}

Calcium chloride dihydrate $\left(\mathrm{CaCl}_{2} \cdot 2 \mathrm{H}_{2} \mathrm{O}\right)$ was used to prepare simulated spent 


\begin{tabular}{lc}
\hline Additive & Concentration \\
\hline \hline VES-A & $6 \mathrm{vol} \%$ \\
Corrosion inhibitor & $0.5-2 \mathrm{vol} \%$ \\
Formic acid & $2-5 \mathrm{wt} \%$ \\
Methanol & $5-10 \mathrm{vol} \%$ \\
Mutual solvent & $10 \mathrm{wt} \%$ \\
Citric acid & $0.5 \mathrm{wt} \%$ \\
EDTA & $0.5 \mathrm{wt} \%$ \\
Non-emulsifying agent & $0.5 \mathrm{wt} \%$ \\
$\mathrm{H}_{2} \mathrm{~S}$ scavenger & $0.5 \mathrm{wt} \%$ \\
\hline
\end{tabular}

Table 2.2: Concentrations of additives examined.

acid solutions. Relying on the mass balance calculation of the reaction between $\mathrm{HCl}$ and $\mathrm{CaCO}_{3}, \mathrm{CaCl}_{2}$ at a concentration of $23 \mathrm{wt} \%$ was used to represent spent $\mathrm{HCl}$ at a concentration of $15 \mathrm{wt} \% \cdot \mathrm{CaCl}_{2} \cdot 2 \mathrm{H}_{2} \mathrm{O}$ is dissolved in deionized water. Hydration of $\mathrm{CaCl}_{2}$ is an exothermic process, so the solution was stirred till the temperature reaches to the room temperature. Following this step, corrosion inhibitor at 0.5 vol\% concentration and other additives at desired concentrations were added. Finally, VES-A mixed with the solution while stirring. Surfactant added to the solution quickly and stirring rate was controlled in order to prevent unwanted foaming. Final blend mixed at a high stirring rate for 15 minutes.

\subsubsection{Rheological Tests}

A high pressure-high temperature rotational rheometer was used to establish viscosity measurements. The sample cup was filled with the acid mixture, and the depressurization valve at the bottom of the cup was tightened to prevent any leak. The bob was attached to the rod, and the cup was installed to the screw-threaded section. The oil bath was lifted to a certain level that properly covered the cup. A nitrogen tank was used to apply a pressure of 300 psi to keep the evaporation 
of the sample at the minimum level. Using the software of the equipment, desired conditions such as temperature and shear rate and time were set. The experiment was started, and all data was recorded via software. After the viscosity measurement was completed, the oil bath was lowered and the temperature of the sample cup was allowed to drop below $100^{\circ} \mathrm{F}$ for a safe sample disposal. The valve on the nitrogen tank was closed. With the help of the valve at the bottom of the cup, the system was depressurized and the sample was collected at the same time. Finally, the sample cup was removed and the equipment components were cleaned. 


\section{RESULTS AND DISCUSSION}

Viscoelastic surfactant-based acid systems were prepared as live and spent acids. Live acid solutions included 15 wt $\% \mathrm{HCl}, 6 \mathrm{vol} \% \mathrm{VES}-\mathrm{A}$ and 0.5 vol $\%$ corrosion inhibitor (CI). For each experiment, desired acid additives were incorporated keeping the final concentrations of $\mathrm{HCl}, \mathrm{VES}$ and corrosion inhibitor constant at stated values. To prepare the spent acids, $\mathrm{HCl}$ was replaced with $\mathrm{CaCl}_{2}$ at concentration of 23 wt\%. Doing so stimulated the reaction between $\mathrm{HCl}$ and $\mathrm{CaCO}_{3}$, where $\mathrm{HCl}$ is totally consumed and $\mathrm{CaCl}_{2}$ is produced. $\mathrm{pH}$ values of the spent acids were found to be in the range of 1.5 to 2 with the effect of corrosion inhibitor acidity. The

temperature effect at a $100 \mathrm{~s}^{-1}$ shear rate and shear rate dependence at ambient temperature were tested for each sample. A pressure of 300 psi was applied during all measurements to minimize the evaporation of sample.

\subsection{Effect of Surfactant Concentration on Apparent Viscosity}

Viscosity of the VES-based formulations show a strong relation with the surfactant concentration in the solution. Zana and Kaler (2007) explains this relation indicating that changing the surfactant concentration causes differentiation in micelle structure. The number of surfactant molecules in the solution affects the micelle structure, length and extent of entanglement. To be able to comprehend the effect of viscoelastic surfactant concentration on the apparent viscosity of VES-based acid, spent acids were prepared with $23 \mathrm{wt} \% \mathrm{CaCl}_{2}, 0.5$ vol\% corrosion inhibitor and varying VES-A concentrations from 2 to 8 vol\%. Fig.3.1 shows the effect of concentration as a function of temperature for the solutions at a shear rate of $100 \mathrm{~s}^{-1}$ and $300 \mathrm{psi}$ pressure. 
The solutions with 2 and 4 and vol\% of VES-A resulted an initial rise in the viscosity as the temperature gradually increased, and followed a slightly declining trend as the temperature continued to rise. Spent acid with 6 vol\% VES-A showed an initial increase in the apparent viscosity and maintained the high viscosity trend. Contrarily, increase of the VES concentration altered the behavior of the micelles, and 8 vol\% VES-A caused an initial drop in the viscosity. Depending on these rheology patterns, 6 vol\% of VES-A was determined as the optimum surfactant concentration for this study.

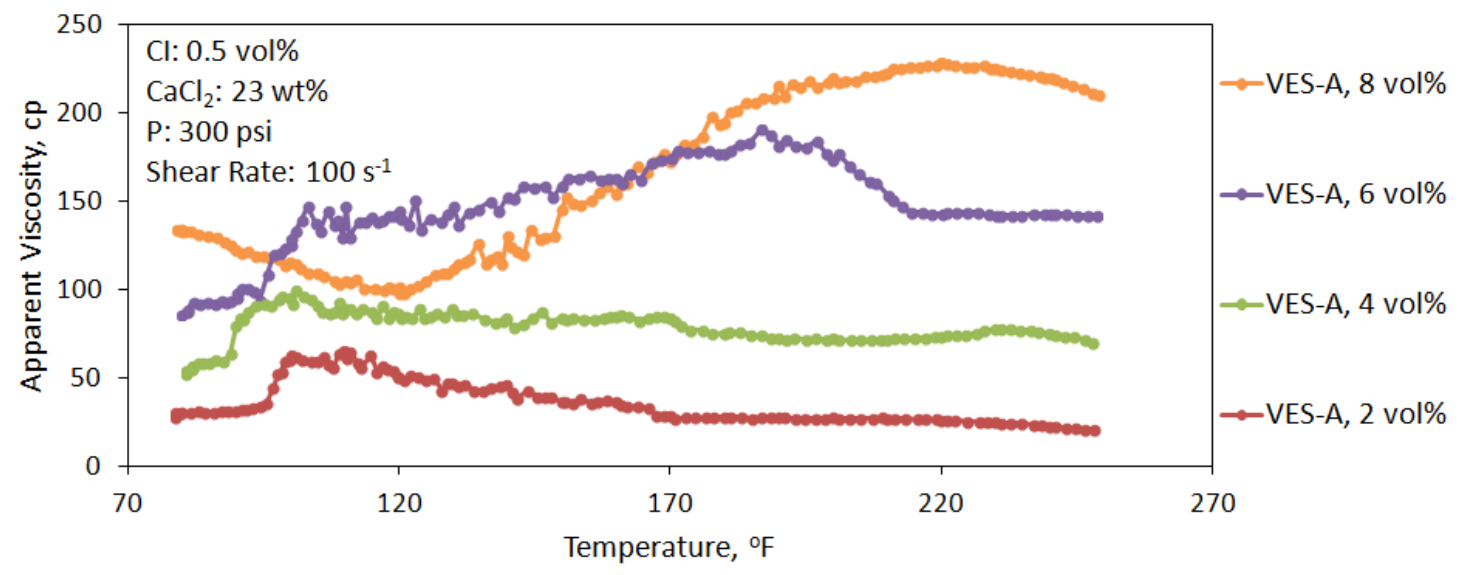

Figure 3.1: Effect of VES concentration and temperature on the on the apparent viscosity of spent acid.

\subsection{Effect of Temperature on Apparent Viscosity}

In oil field applications, maintaining a good VES-based acid viscosity at high temperatures is a challenge. Conventional VES-based acid applications are limited to approximately $200^{\circ} \mathrm{F}$ (Taylor et al. 2003). To examine the temperature resistance of VES-A, a spent acid blend was prepared consisting of 6 vol\% VES, 0.5 vol\% corrosion inhibitor and $23 \mathrm{wt} \% \mathrm{CaCl}_{2}$. Viscosity was measured at temperature range between 
78 and $350^{\circ} \mathrm{F}$ (Fig. 3.2). It is noted that the solution gained maximum viscosity at the temperature range between 180 and $240^{\circ} \mathrm{F}$. Further increase in the temperature caused a viscosity degradation. Reaching to the temperature of $270^{\circ} \mathrm{F}$, apparent viscosity reduced below $80 \mathrm{cp}$ at $100 \mathrm{~s}^{-1}$. In the literature, temperature dependency of the surfactant-based fluids viscosity is explained on the basis of the scission of the micelles (Cates and Candau 1990). As the length of the rod-like micelles decreases, the extent of the entanglement decreases which causes the viscosity reduction.

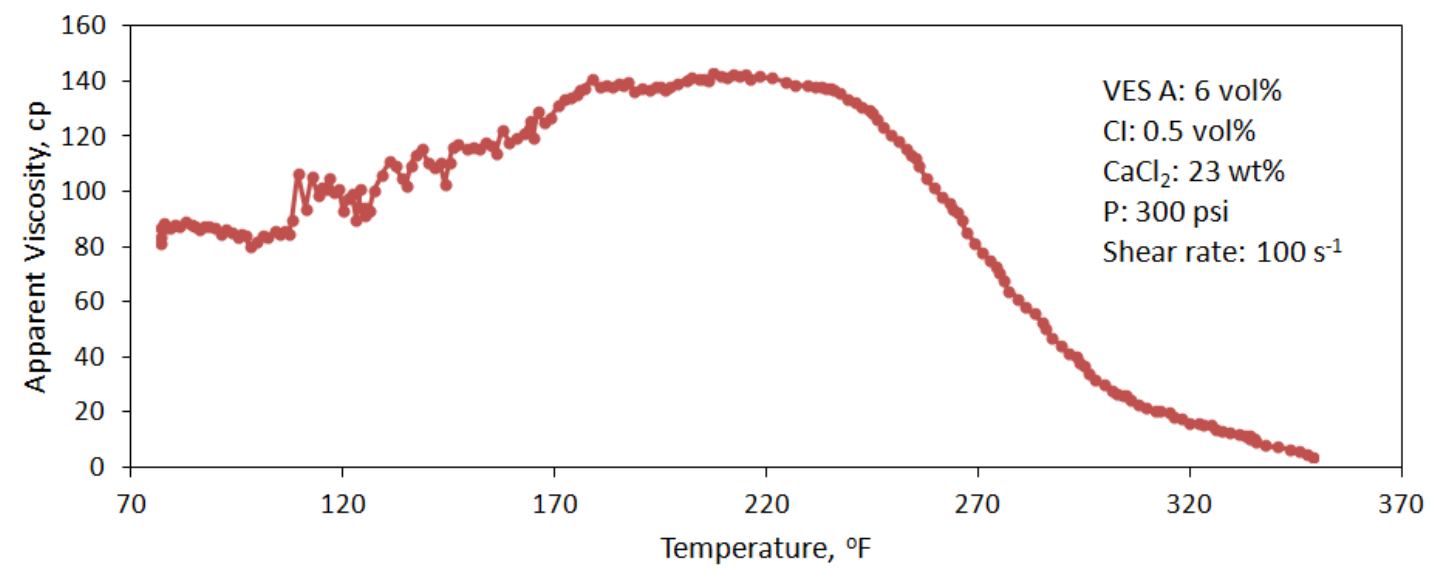

Figure 3.2: Temperature limitation on the apparent viscosity of VES-A based spent acid.

3.3 Effect of Salt Type and Concentration on the Apparent Viscosity

\subsubsection{Effect of $\mathrm{CaCl}_{2}$ Concentration}

To be able to investigate the effect of salt concentration on the rheology, VESbased acid systems consisting of 6 vol\% VES, 0.5 vol\% corrosion inhibitor and $\mathrm{CaCl}_{2}$ at various concentrations were tested. By using different $\mathrm{CaCl}_{2}$ concentrations, it was aimed to evaluate the alteration of the apparent viscosity of the stimulation fluid as the acid reacts with $\mathrm{CaCO}_{3}$ and produce $\mathrm{CaCl}_{2}$ in the formation. Concentrations 
of 10, 15, 23 and $30 \mathrm{wt} \% \mathrm{CaCl}_{2}$ were used to represent spent $\mathrm{HCl}$ concentrations of $6.6,9.8,15$ and $20 \mathrm{wt} \%$, respectively.

Fig.3.4 depicts the relation between the viscosity and temperature for each solution. Shear rate was kept at a constant value of $100 \mathrm{~s}^{-1}$, and temperature was increased gradually. It is noted that the solutions with 10 and 15 wt\% $\mathrm{CaCl}_{2}$ concentrations showed an increasing viscosity trend, reached a peak and showed decline as the temperature steadily increased. Viscosity of spent acid consisting of $23 \mathrm{wt} \%$ $\mathrm{CaCl}_{2}$ yielded a sudden increase as with the increased temperature, and resulted a stable pattern with the highest viscosity values at temperatures above $170^{\circ} \mathrm{F}$. However, further increase of the salt concentration caused a dramatic decline in the viscosity of the VES-based spent acid. As seen in the Fig.3.4, 30 wt\% $\mathrm{CaCl}_{2}$ curve yielded the lowest apparent viscosity values at temperatures up to $220^{\circ} \mathrm{F}$. This negative influence of the increased salt concentration on the rheology is explained with the modification of the micellar morphology (Lequeux 1996, Candau et al. 1993). The energy required to form end-cap becomes higher than the energy required to form branches, and micelles form a branched network of junctions rather than maintaining linear rod-like structures (Fig. 3.3).

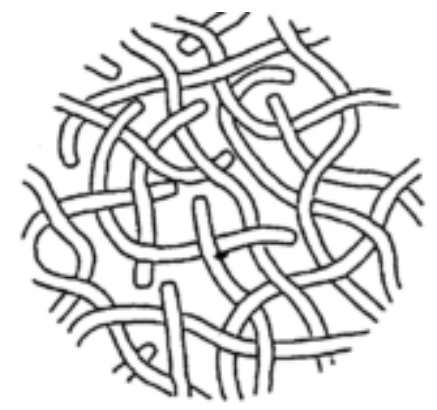

(a) Entangled rod-like micelles.

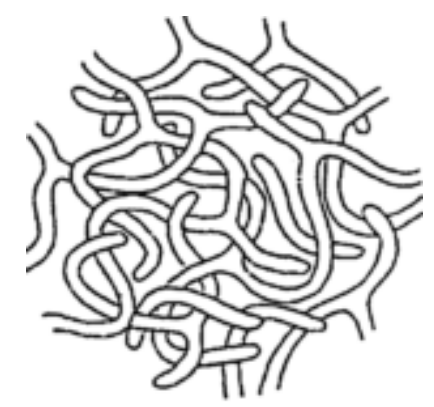

(b) Entangled branched micelles.

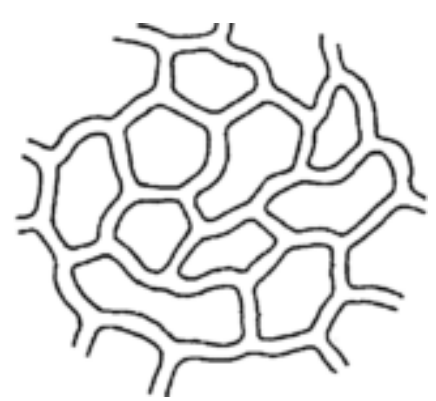

(c) Multiconnected micelle network.

Figure 3.3: Alteration of rod-like micelle structure upon increased salt concentration (Candau et al. 1993). 


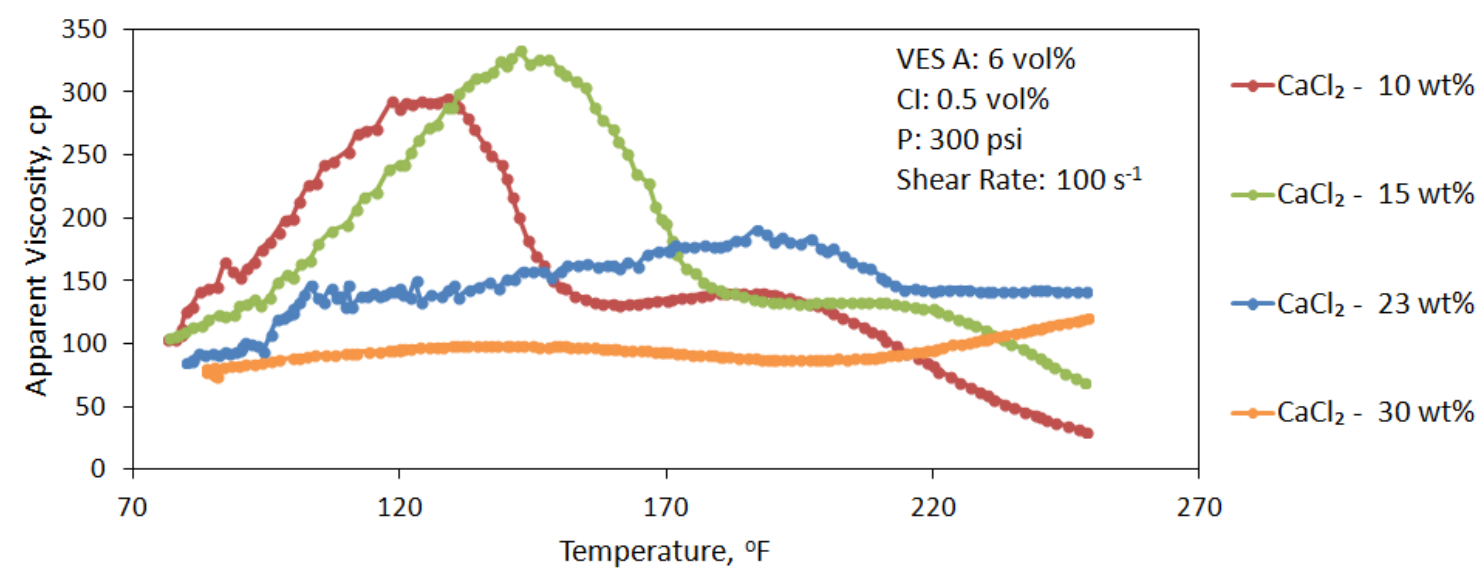

Figure 3.4: Apparent viscosity as a function of temperature for spent acids containing various concentrations of $\mathrm{CaCl}_{2}$.

The relation between the apparent viscosity and shear rate is depicted in Fig. 3.5. All spent acid samples showed shear thinning behavior. For high salt concentrations, 23 and 30 wt\%, decreasing viscosity patterns were found to be more steady.

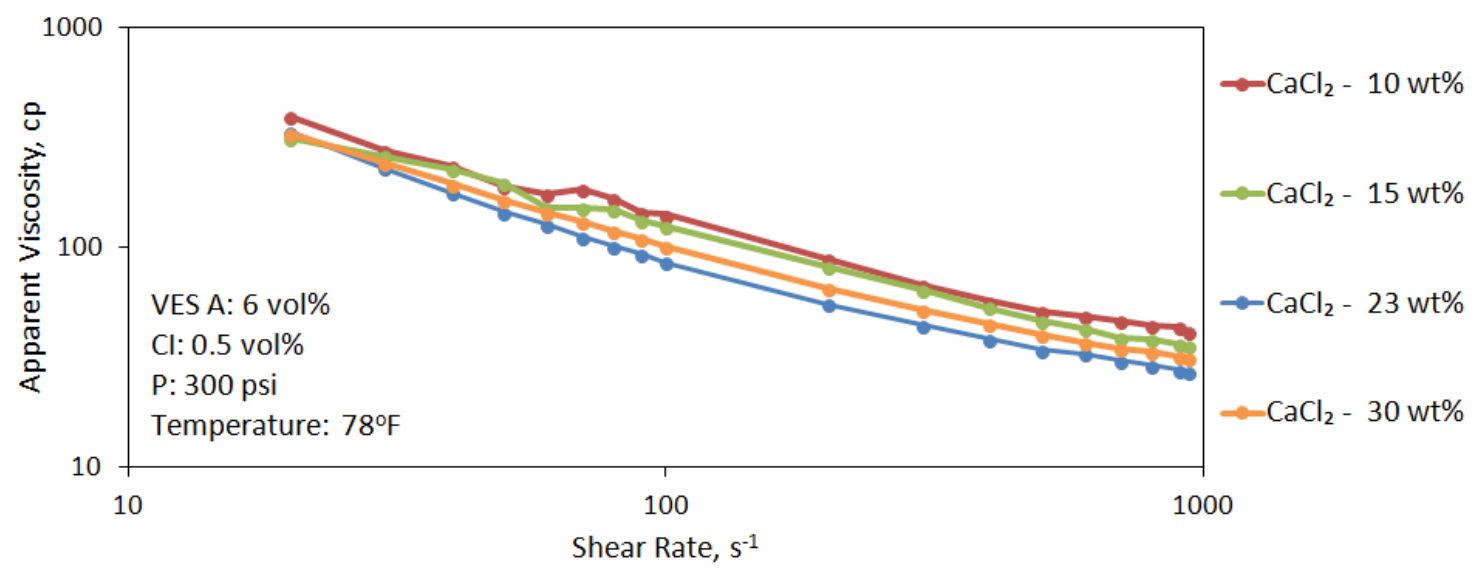

Figure 3.5: Apparent viscosity as a function of shear rate for spent acids containing various concentrations of $\mathrm{CaCl}_{2}$. 


\subsubsection{Effect of Salt Type}

Effects of cation valency on the rheology of the solution were tested by measuring the viscosity of the samples prepared with 6 vol\% VES, 0.5 vol\% corrosion inhibitor and 10 wt $\%$ salt. $\mathrm{CaCl}_{2}, \mathrm{MgCl}_{2}, \mathrm{NaCl}$ and $\mathrm{KCl}$ salts were used for this purpose. Fig. 3.6 depicts the effect of temperature and salt type on the apparent viscosity of these solutions. Divalent cations $\left(\mathrm{Mg}^{2+}\right.$ and $\mathrm{Ca}^{2+)}$ caused a sharp increase and reached a peak as the temperature gradually increased. Monovalent cations $\left(\mathrm{Na}^{+}\right.$ and $\mathrm{K}^{+}$) cations in the solution resulted a slight viscosity increase and a sudden decline at about $120^{\circ} \mathrm{F}$. It is concluded that between the temperatures of 120 and $170^{\circ} \mathrm{F}$, electrostatic interactions of divalent ions and viscoelastic surfactant molecules were more influential on the dynamics of micelle assembling. At higher temperatures, however, the difference in the apparent viscosity due to valency of cations diminished and viscosity of all solutions started declining as shown in Fig. 3.6.

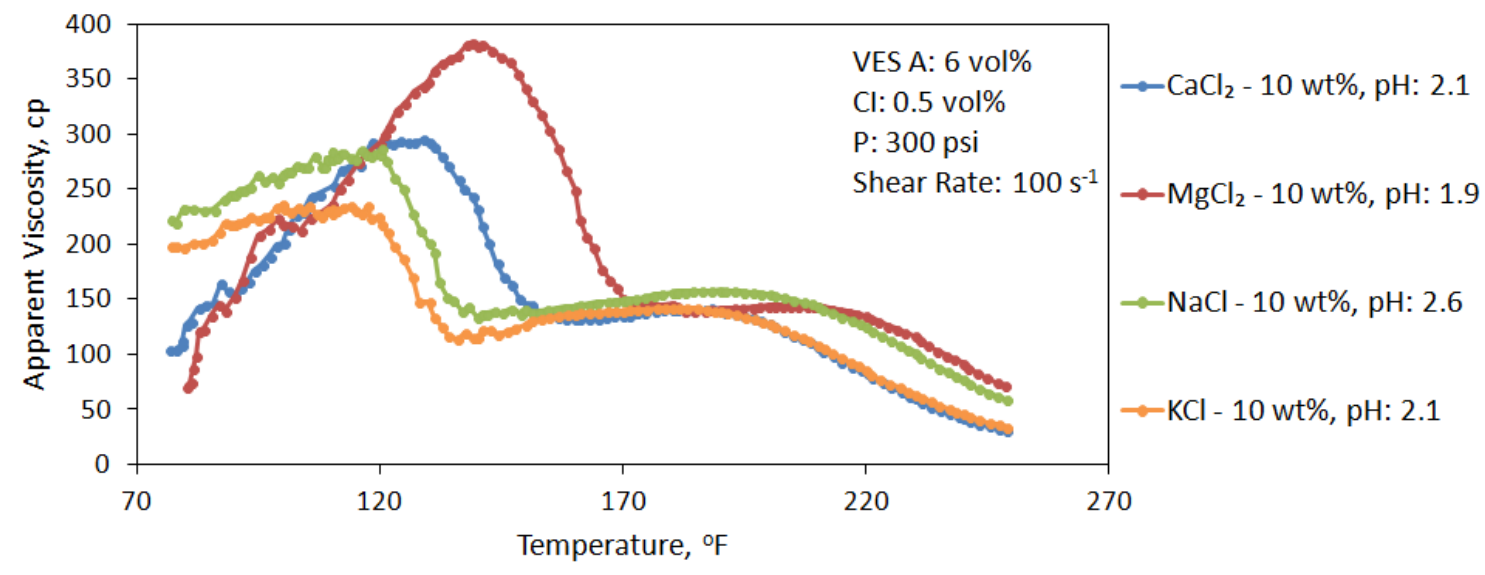

Figure 3.6: Effect of cation type on the apparent viscosity as a function of temperature. 


\subsection{Apparent Viscosity of Live Acids}

Apparent viscosity of the VES-based live acid was lower than the apparent viscosity of spent acids, usually below $30 \mathrm{cp}$. This feature of the VES-based acid provides an easier acid injection process in field applications.

\subsubsection{Effect of Corrosion Inhibitor Concentration}

Since the VES-based stimulation fluid is injected to the well in live condition, a compatible corrosion inhibitor usage is essential to protect the tubular. Impact of corrosion inhibitor concentration on the live acid rheology was tested adding $0.5,1$ and 2 vol\% of corrosion inhibitor to the live acid blends. The apparent viscosity as a function of temperature is measured at a shear rate of $100 \mathrm{~s}^{-1}$ and 300 psi (Fig. 3.7). For all corrosion inhibitor concentrations, the viscosity was less than $5 \mathrm{cp}$ at temperatures up to $200^{\circ} \mathrm{F}$. After this point, viscosity started increasing and made a peak at about $220^{\circ} \mathrm{F}$. Further increase in the temperature caused a sudden viscosity drop. It was observed that increased corrosion inhibitor concentration caused reduction of the apparent viscosity. Reason of this drop is explained in section 3.5.1.

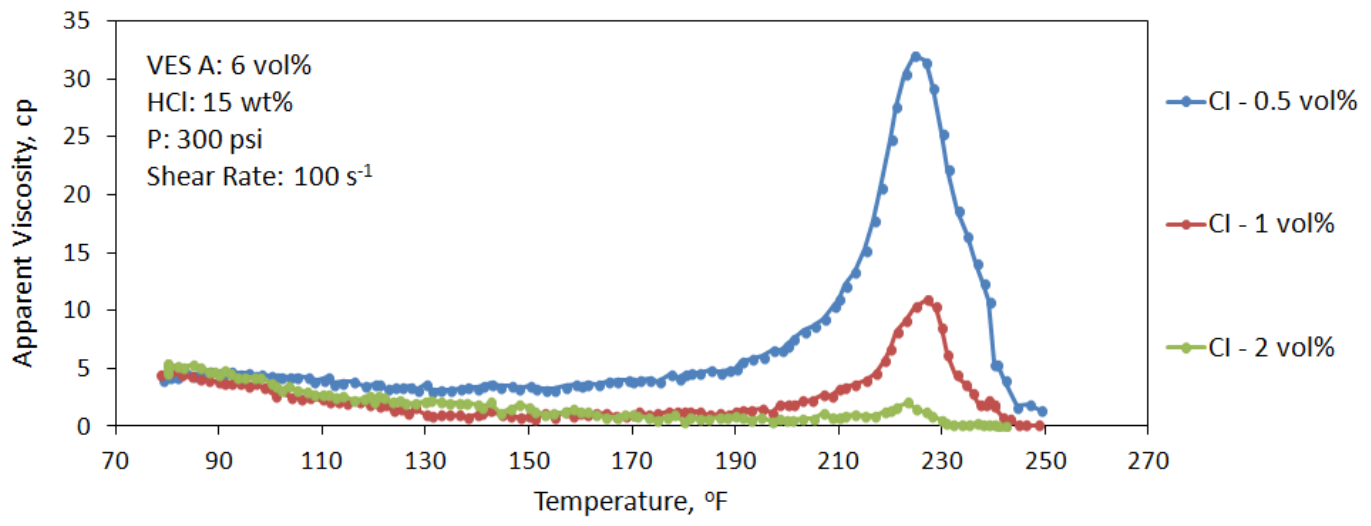

Figure 3.7: Effect of temperature on the apparent viscosity of live acid systems including 6 vol\% VES A and various concentrations of corrosion inhibitor. 
Shear history dependencies of the solutions prepared at different corrosion inhibitor concentrations are depicted in Fig. 3.8. Apparent viscosity values were measured at room temperature. The shear rate increased gradually starting from 20 to $935 \mathrm{~s}^{-1}$, and then decreased back to initial point. The live acids were not able to regain their initial viscosities after being exposed to high rates of shearing.

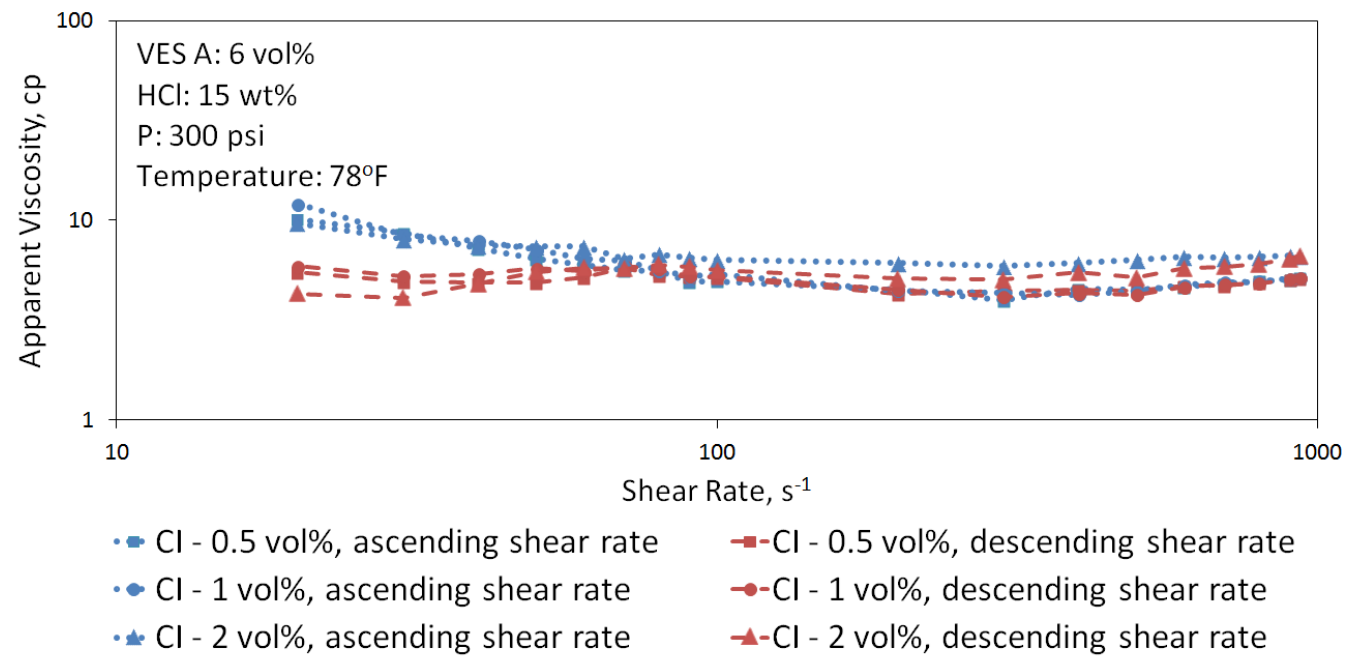

Figure 3.8: Shear history dependence of the apparent viscosity of live acid systems including 6 vol\% VES A and various concentrations of corrosion inhibitor.

\subsubsection{Effect of Methanol}

In acid treatments, methanol is added to the acid blend to decrease the surface tension and ease clean up of the spent acid after the treatment. To investigate the impact of methanol on the apparent viscosity of the VES-based acid, the experiments were conducted keeping the concentrations of VES-A, $\mathrm{HCl}$, and corrosion inhibitor at constant values of $6 \mathrm{vol} \%, 15 \mathrm{wt} \%$ and $0.5 \mathrm{vol} \%$, respectively. Methanol concentration varied form 0 to $10 \mathrm{vol} \%$. Addition of methanol to live acid blends negatively affected the micelle generation and resulted a water-like viscosity at all temperatures (Fig. 
3.9). The solutions showed dependency on shear history as seen in Fig. 3.10. Initial apparent viscosity were not regained after shearing desisted.

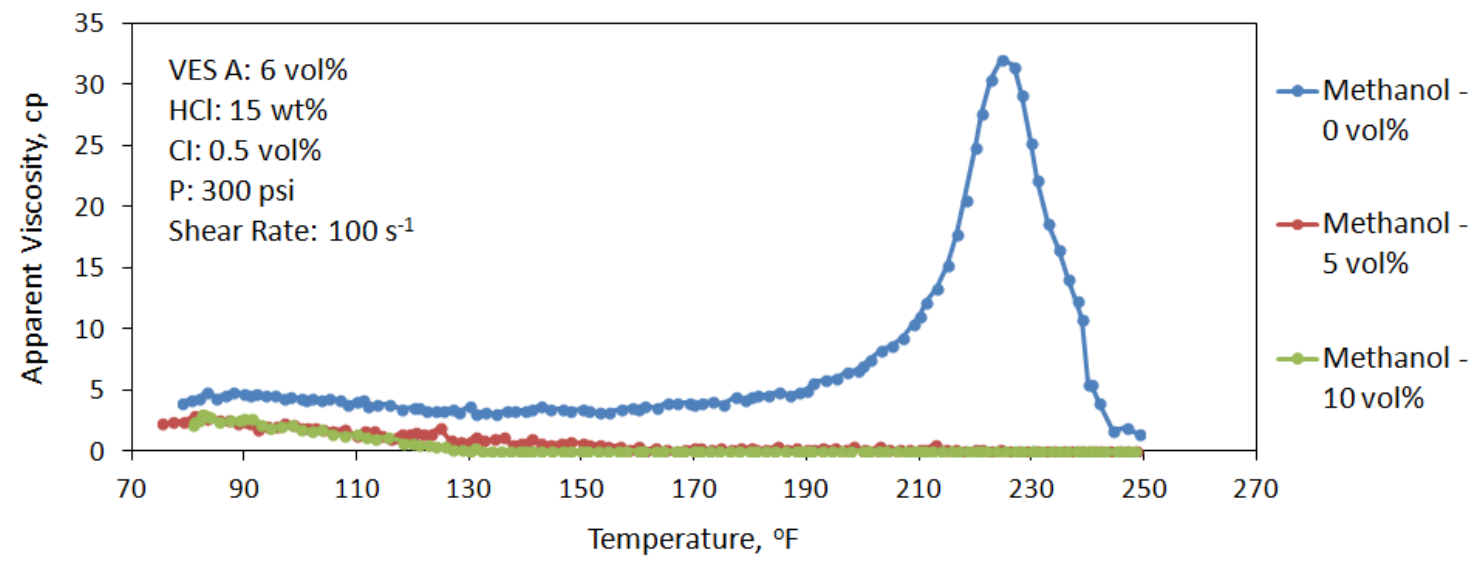

Figure 3.9: Effect of methanol concentration and temperature on the viscosity of live acids containing 6 vol\% VES $A$ and 0.5 vol\% corrosion inhibitor.

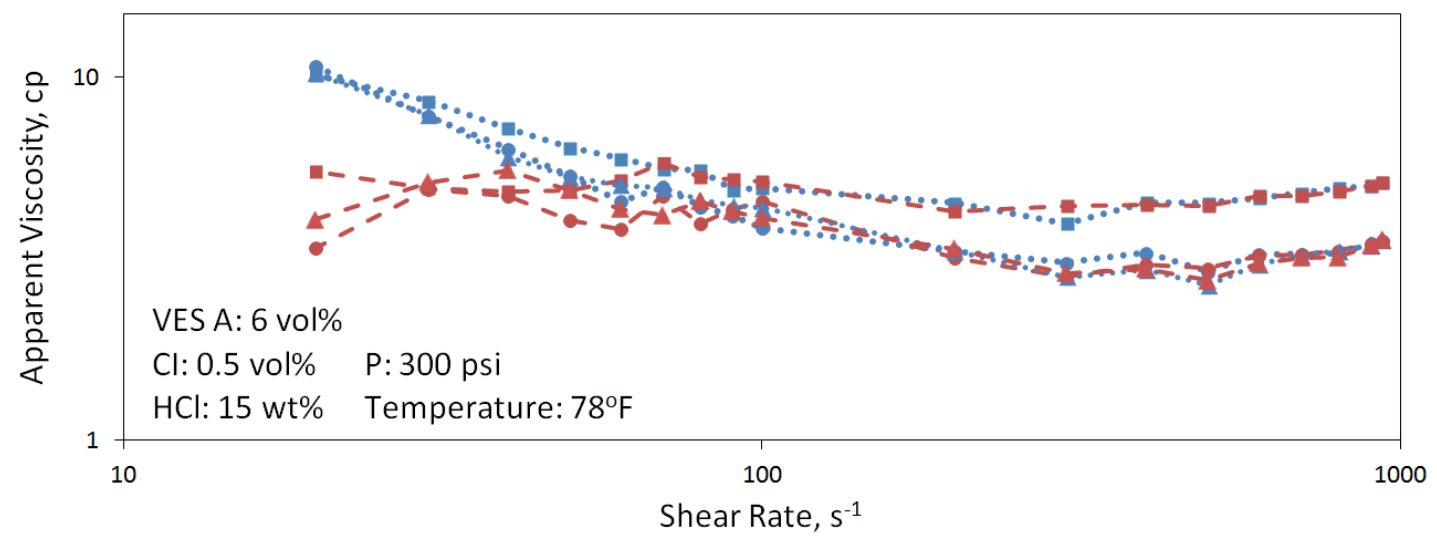

- Methanol-0 vol\%, ascending shear rate $\rightarrow-M e t h a n o l-0$ vol\%, descending shear rate
-. Methanol-5 vol\%, ascending shear rate $\rightarrow$ Methanol-10 vol\%, ascending shear rate $\rightarrow-M e t h a n o l-5$ vol\%, descending shear rate
- Mol\%, descending shear rate

Figure 3.10: Shear history dependence of live acid systems containing 6 vol\% VES A, 0.5 vol\% corrosion inhibitor and various concentrations of methanol. 


\subsubsection{Effect of Iron Contamination}

Iron precipitation is one of the biggest concerns during acid stimulation applications. Iron can present in the acid solutions due to contamination, dissolution of rust in the storage tanks or tubulars, minerals including iron in the formation, or corrosion products in the wellbore. Some forms of iron compounds are soluble in the acid; however, they can precipitate as the acid is spent. Taylor et al. (1999) indicated that iron(III) hydroxide starts precipitating above $\mathrm{pH}$ values of 1 , and completely precipitates at approximately $\mathrm{pH} 2$, at $77^{\circ} \mathrm{F}$. Iron also causes problems interacting with the surfactant molecules in VES-based acid (Al-Nakhli et al. 2008, Shu et al. 2015).

To understand the effect of iron on the rheology of VES-based acid, viscosity measurements for live acids consisting of $15 \mathrm{wt} \% \mathrm{HCl}, 0.5 \mathrm{vol} \%$ corrosion inhibitor and $0.5 \mathrm{wt} \% \mathrm{FeCl}_{3}$, were conducted. $\mathrm{Fe}(\mathrm{III})$ presence in the live acid caused the apparent viscosity to increase due to generation of iron-VES complex. As the temperature increased (Fig. 3.11, the viscosity showed a rising trend and made a peak at about $150^{\circ} \mathrm{F}$, reaching to a viscosity of $280 \mathrm{cp}$. The apparent viscosity declined with further increase of temperature. The fluid showed dependence on the shear history as shown in Fig. 3.12. 


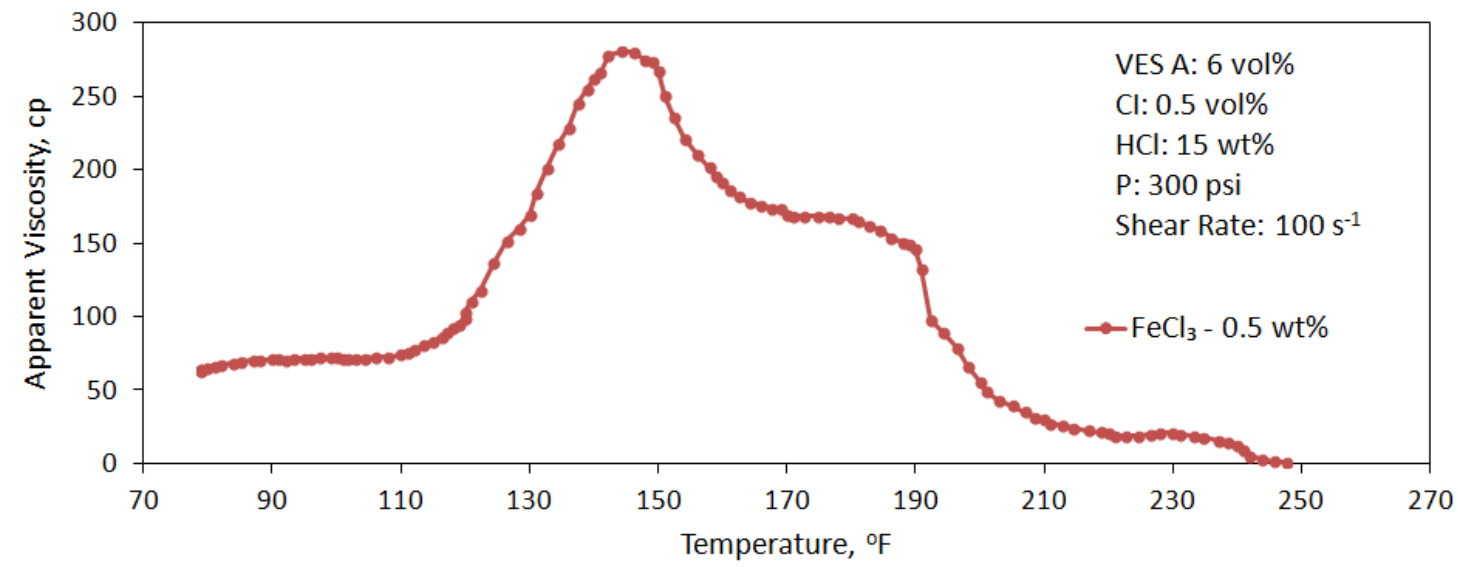

Figure 3.11: Apparent viscosity as a function of temperature for live acid with iron contamination.

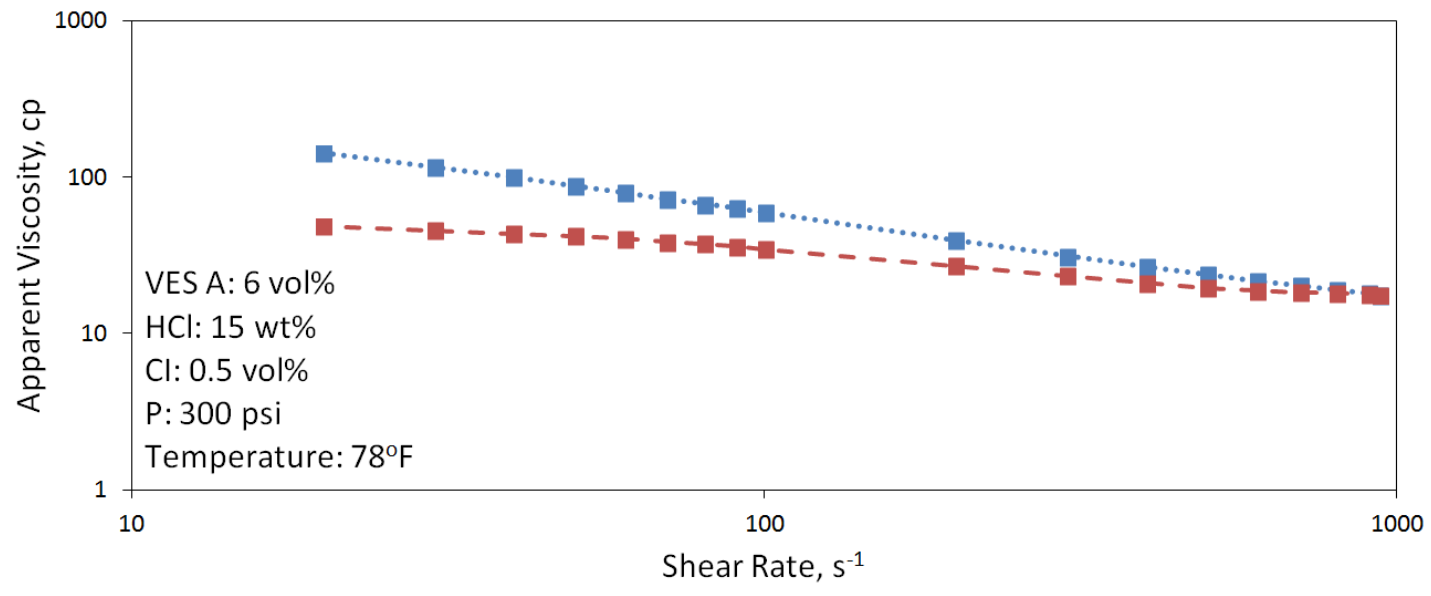

$\cdot \cdot \cdot \mathrm{FeCl}_{3}-0.5 \mathrm{wt} \%$, ascending shear rate $-\mathrm{FeCl}_{3}-0.5 \mathrm{wt} \%$, descending shear rate

Figure 3.12: Apparent viscosity as a function of shear rate for live acid with iron contamination. 
A comprehensive investigation about VES-iron interaction was conducted by Shu et al. (2015). It is proposed that the anionic part $\left(\mathrm{R}_{-} \mathrm{SO}_{3}^{-}\right)$of the zwitterionic surfactant is protonated $\left(\mathrm{R}-\mathrm{SO}_{3} \mathrm{H}\right)$ at low $\mathrm{pH}$ environment. The cationic part $\left(\mathrm{R}_{-} \mathrm{N}^{+}\right)$of the surfactant and $\mathrm{Fe}^{+3}$ ions do not directly interact. However, $\mathrm{Fe}^{3+}$ can react with $\mathrm{Cl}^{-}$ions in the solution forming $\mathrm{FeCl}_{4}^{-}$(Eq. 3.2). $\mathrm{FeCl}_{4}^{-}$complex with the positively charged center of the VES increasing in the apparent viscosity.

$$
\begin{aligned}
& R-S_{3}^{-}+H^{+} \rightleftharpoons R-S O_{3} H \\
& F e^{3+}+4 C l^{-} \rightleftharpoons \mathrm{FeCl}_{4}^{-}
\end{aligned}
$$

\subsection{Apparent Viscosity of Spent Acids}

Since the viscosity of the VES-based acid in spent condition is the major determinant for acid diversion and leakoff control in acid stimulation applications, it is important to ensure that spent acid, including various acid additives, provides and maintains a sufficient viscosity for a successful treatment at different conditions. To do so, optimal concentration for common acid additives should be determined considering rheological behavior of the spent acid. This section of the study aims to examine effects of some common acid additives on the viscosity of the spent acid.

Contrary to live acid, VES-A resulted high viscosity values in the simulated spent acid solutions, depending on the nature of the examined acid additives. the reason of this increase is explained with the increased ph of the medium and salt concentration in the solution due to reaction of $\mathrm{HCl}$ with the minerals. Apparent viscosity was not sensitive to shear history since the micelle association is electrostatic in character. When the micelle aggregation is discomposed due to shear, molecules were able assemble back after shear desists recreate initial viscosity. 


\subsubsection{Effect of Corrosion Inhibitor Concentration}

The effect of temperature on the spent acid solutions including corrosion inhibitor at concentrations of $0.5,1$ and $2 \mathrm{vol} \%$, at a shear rate of $100 \mathrm{~s}^{-1}$ and at $300 \mathrm{psi}$, is illustrated in Fig. 3.13. As the corrosion inhibitor concentration was increased, the apparent viscosity was declined note-worthily with the increased temperature.

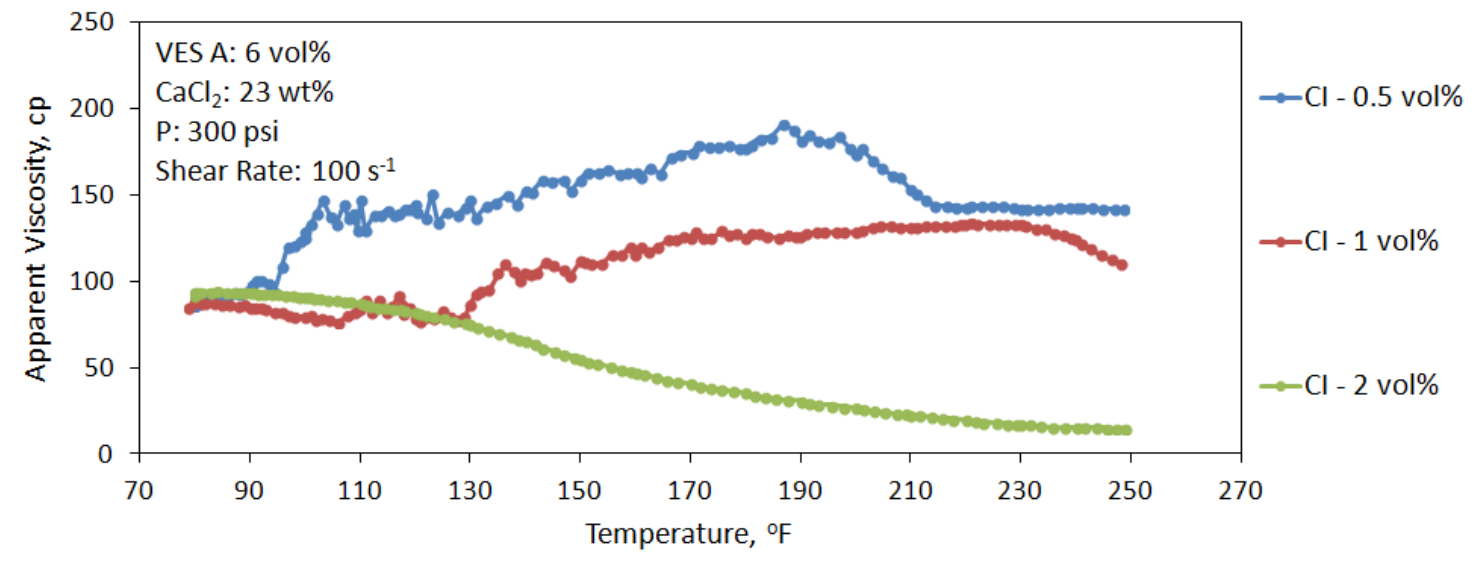

Figure 3.13: Effect of temperature on the apparent viscosity of spent acid systems including 6 vol\% VES A and various concentrations of corrosion inhibitor.

Shear sweep tests showed that apparent viscosity decreased with the increased shear rate, but all solutions were able to recover their viscosity as the shear rate started decreasing back (Fig. 3.14).

Table 3.1 presents the composition of the corrosion inhibitor used, where high formic acid concentration and ispropanol content stand out. Several studies on micellization showed that presence of formic acid and short chain alcohols in the micellar solutions adversely affect the intermicellar interaction, which leads to scission of rodlike micelles and viscosity loss as a result (Candau and Zana 1981, Hong and Kuboi 1999, Li et al. 2011). 


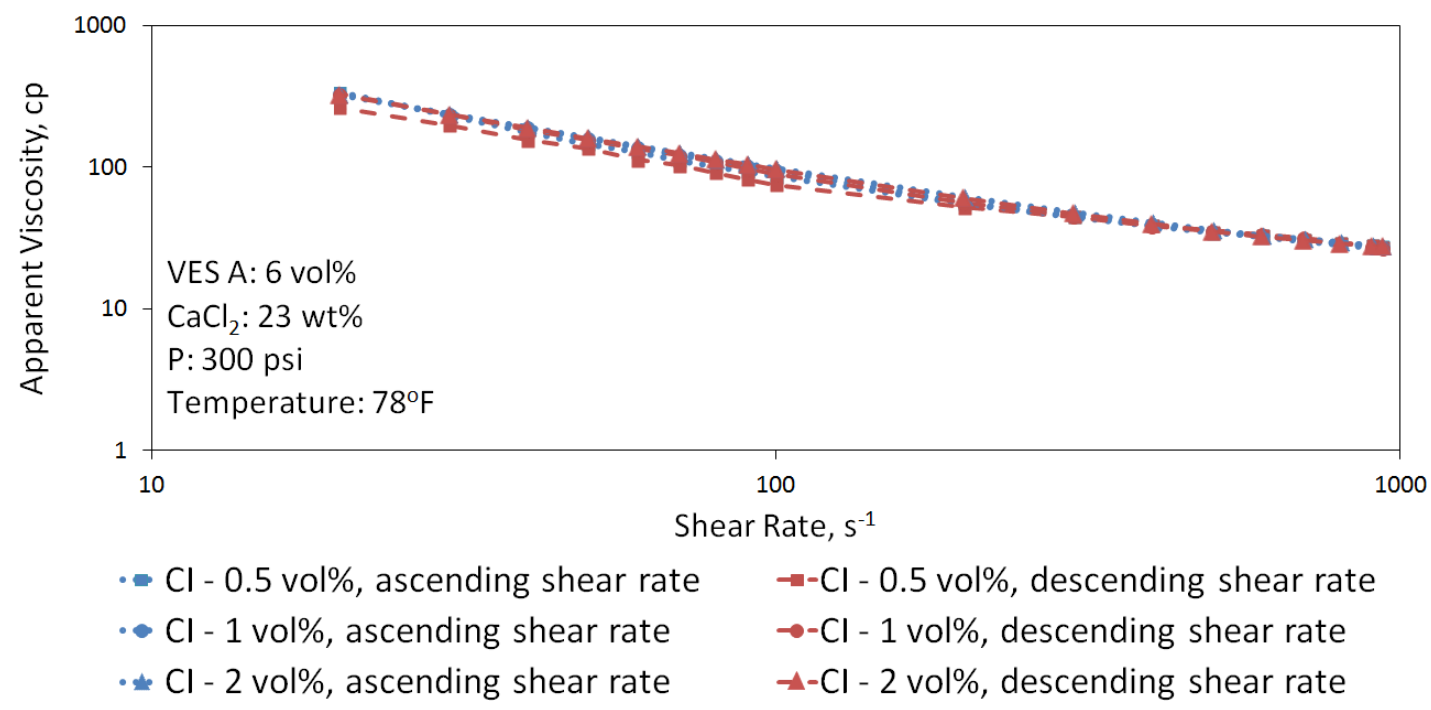

Figure 3.14: Shear history dependence of the apparent viscosity of spent acid systems including 6 vol\% VES A and various concentrations of corrosion inhibitor.

To validate this conclusion, the effect of the formic acid on the viscosity was also examined. $2 \mathrm{wt} \%$ of formic acid included in the spent acid in addition to $0.5 \mathrm{vol} \%$ corrosion inhibitor and apparent viscosity was measured as a function of temperature. As shown in Fig. 3.15, increased formic acid concentration in the spent acid led to a significant viscosity reduction.

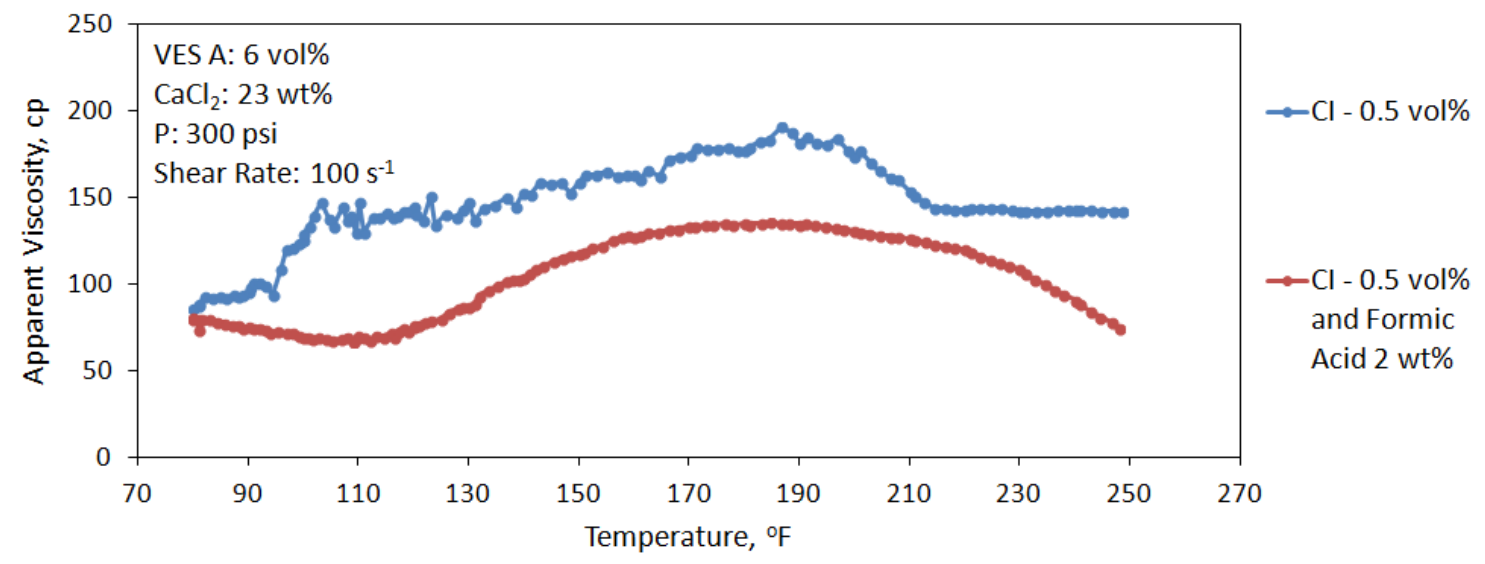

Figure 3.15: Effect of increased formic acid concentration on the apparent viscosity of spent acid as a function of temperature. 


\begin{tabular}{lcc}
\hline Components & Chemical Structure & $\begin{array}{c}\text { Concentration } \\
(\text { wt\%) }\end{array}$ \\
\hline \hline Formic acid & & $10-20$ \\
Isopropanol & & $5-10$ \\
Dimethylformamide & $\mathrm{Na}_{\text {Sodium iodide }}$ & $5-10$ \\
\hline
\end{tabular}

Table 3.1: Composition of corrosion inhibitor tested.

\subsubsection{Effect of Methanol}

As stated before, negative effects of short chained alcohols on the micellization of different types of surfactants were proven through many studies (Candau and Zana 1981, Zana 1984, Hong and Kuboi 1999). To investigate the effect of methanol on the rheology of VES-based spent acid, methanol was added to the simulated spent acid at concentrations of 5 and $10 \mathrm{vol} \%$ keeping the final concentration of VES at 6 vol\%, corrosion inhibitor at $0.5 \mathrm{vol} \%$ and $\mathrm{CaCl}_{2}$ at $23 \mathrm{wt} \%$. Methanol presence in the solution negatively affected the viscosity buildup as expected. At lower temperatures, 5 vol\% methanol addition did not cause a viscosity reduction unlike 10 vol\% methanol (Fig. 3.16, however the impact of alcohol on micelle assembling was clearly observed at temperatures above $100^{\circ} \mathrm{F}$. The viscosity of the spent acid including $10 \mathrm{vol} \%$ methanol eventually became water-like as the temperature increased up to $250^{\circ} \mathrm{F}$. The shear sweep experiments at room temperature showed that methanol did not affect the ability to regain initial viscosity after being exposed to high shearing (Fig. $3.17)$. 


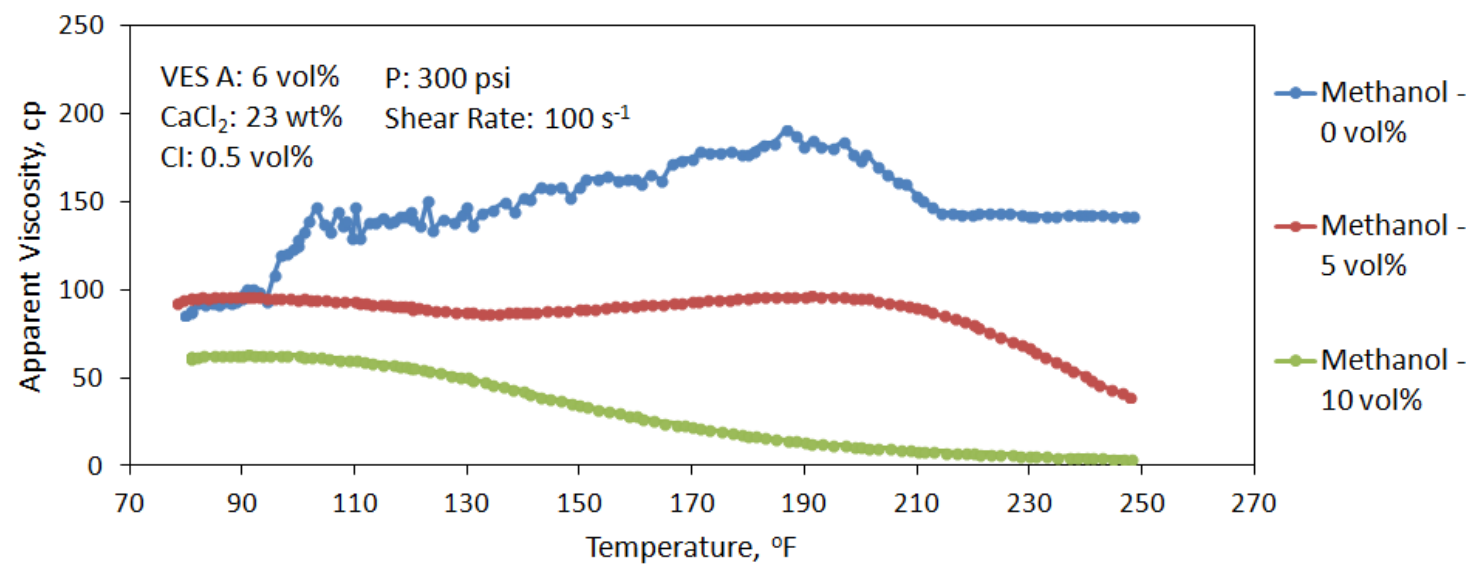

Figure 3.16: Effect of methanol concentration and temperature on the viscosity of spent acid.

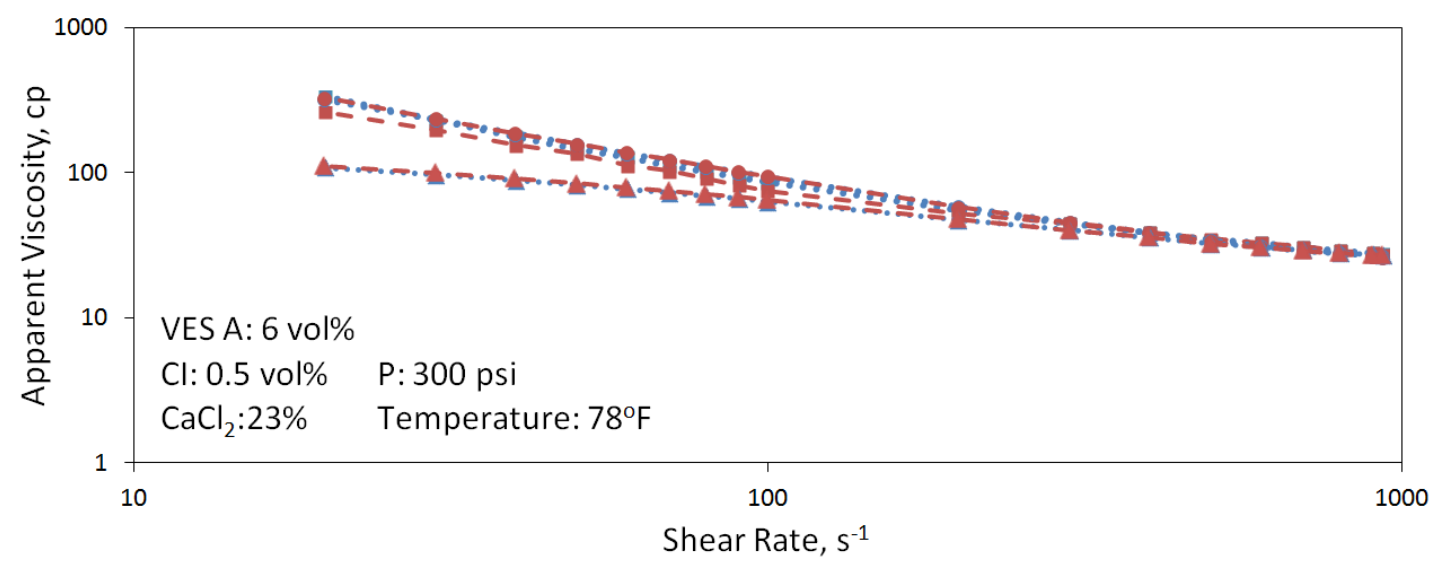

- Methanol-0 vol\%, ascending shear rate $\rightarrow-M e t h a n o l-0$ vol\%, descending shear rate

- Methanol-5 vol\%, ascending shear rate $\rightarrow-M e t h a n o l-5$ vol\%, descending shear rate

- Methanol-10 vol\%, ascending shear rate $\rightarrow-$ Methanol-10 vol\%, descending shear rate

Figure 3.17: Shear history dependence of spent acid systems containing methanol. 


\subsubsection{Effect of Mutual Solvent}

Mutual solvent is an acid additive that is soluble in oil, water and acid-based well stimulation fluids. The purpose of mutual solvent use in acid treatment is to prevent or break acid-oil emulsions, control wettability, and lower the surface tension. Most commonly used mutual solvent, ethyleneglycolmonobutyl ether, also known as EGMBE, was used in this study. Chemical structure of this mutual solvent $\left.\left(\mathrm{C}_{6} \mathrm{H}_{14} \mathrm{O}_{2}\right)\right)$ is shown in Fig. 3.18.

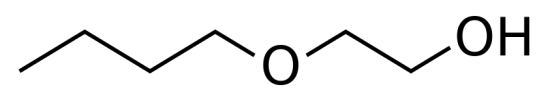

Figure 3.18: Chemical structure of ethylene glycol monobutyl ether.

$5 \mathrm{vol} \%$ and $10 \mathrm{vol} \%$ of mutual solvent were added to the simulated spent acid solution to observe the effect on the flow behavior. Fig. 3.19 shows that viscosity is decreased significantly at all temperatures for both mutual solvent concentrations. Mutual solvent in the solution prevented micelle generation and viscosity buildup. Shear sweep tests also showed that micelles did not present in the solutions. Spent acids did not achieve their original viscosity values after high shearing was applied (Fig. 3.20). 


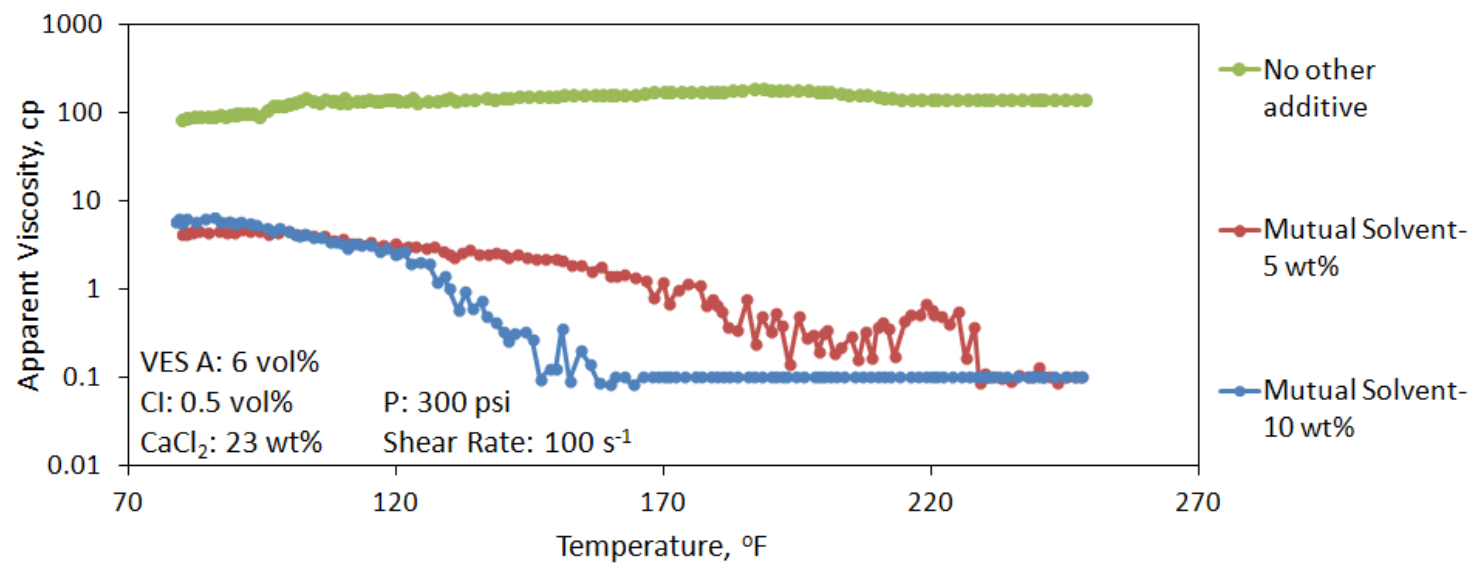

Figure 3.19: Apparent viscosity of spent acid in the presence of mutual solvent.

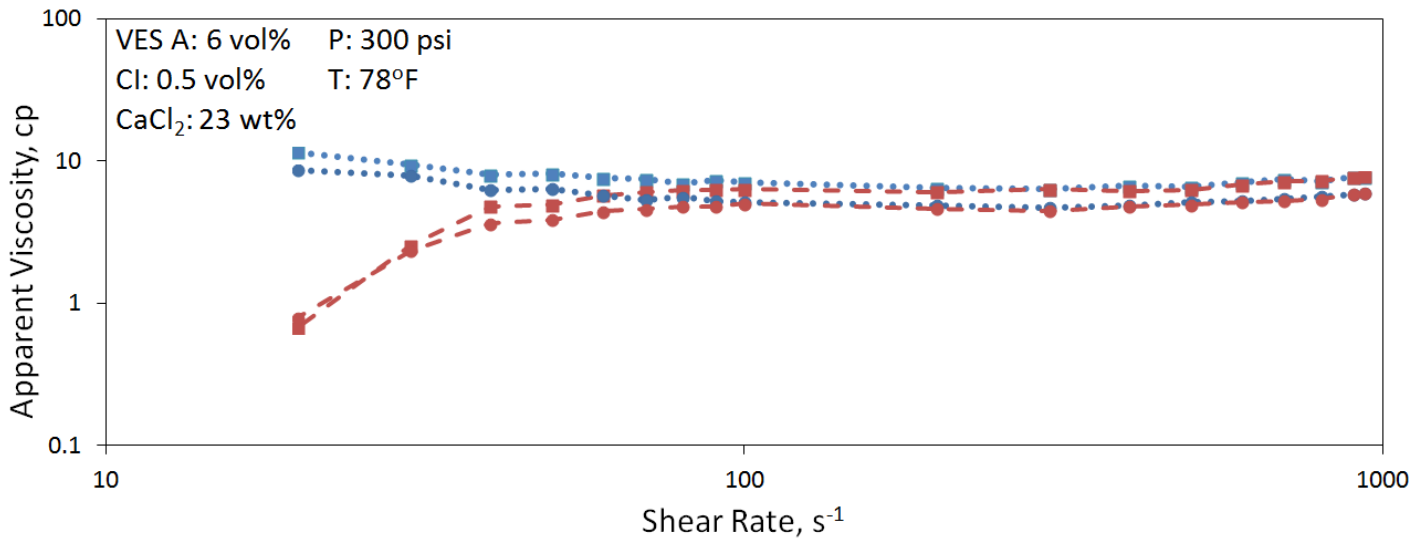

\footnotetext{
- Mutual Solvent- $10 \mathrm{wt} \%$, ascending shear rate $\rightarrow-M u t u a l$ Solvent- $10 \mathrm{wt} \%$, descending shear rate

- Mutual Solvent- $5 \mathrm{wt} \%$, ascending shear rate $\rightarrow-$ Mutual Solvent- 5 wt\%, descending shear rate
}

Figure 3.20: Shear history dependency of spent acid including mutual solvent. 


\subsubsection{Effect of $\mathrm{H}_{2} S$ Scavenger and Demulsifier}

Hydrogen sulphide $\left(\mathrm{H}_{2} \mathrm{~S}\right)$ scavenges are used in the oil industry to convert sulphide species into more inert forms. Thus, safety can be improved due to reduced $\mathrm{H}_{2} \mathrm{~S}$ content and corrosion caused by $\mathrm{H}_{2} \mathrm{~S}$ gas can be reduced. Composition of the $\mathrm{H}_{2} \mathrm{~S}$ scavenger used in this experiment is presented in Table 3.2.

\begin{tabular}{lcc}
\hline Components & Chemical Structure & $\begin{array}{c}\text { Concentration } \\
(\text { wt \%) }\end{array}$ \\
\hline \hline Glyoxal & & $60-70$ \\
Ethylene glycol & & $1-5$ \\
\hline
\end{tabular}

Table 3.2: Composition of $\mathrm{H}_{2} \mathrm{~S}$ scavenger tested.

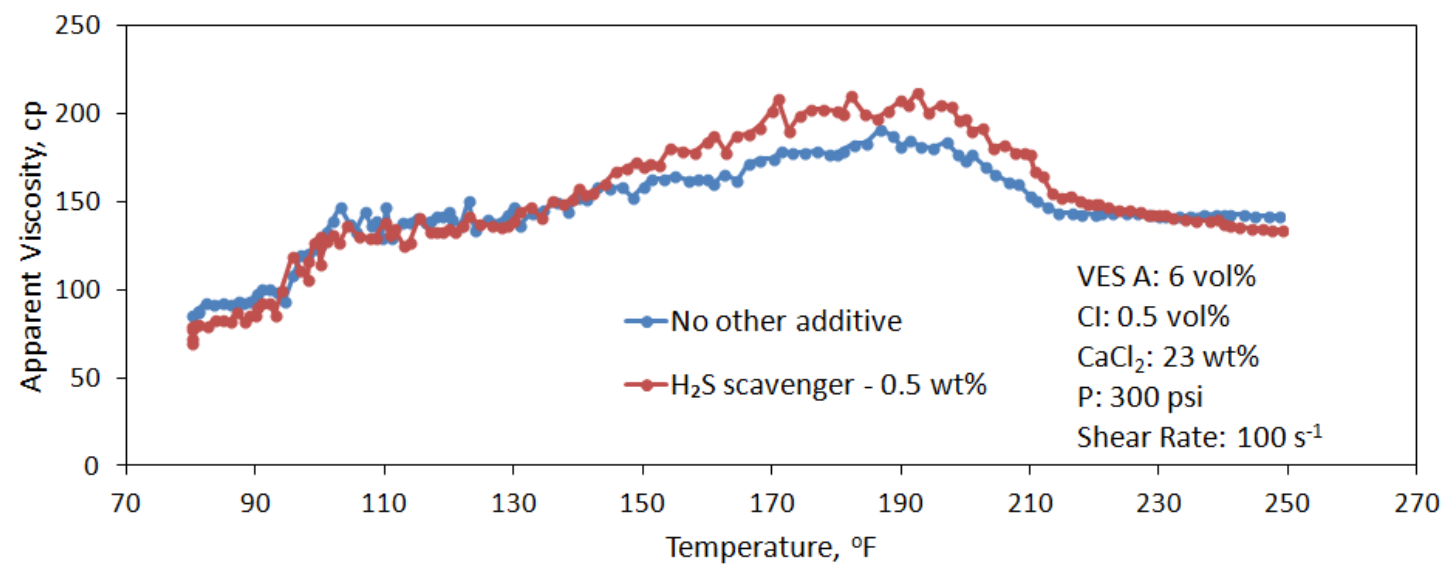

Figure 3.21: Effect of $\mathrm{H}_{2} \mathrm{~S}$ scavenger on apparent viscosity of spent acid as a function of temperature. 
To observe the effects of $\mathrm{H}_{2} \mathrm{~S}$ scavenger on VES-based acid viscosity, scavenger was added to the spent acid blend at a concentration of $0.5 \mathrm{wt} \%$. At low temperature, the scavenger did not change the apparent viscosity of the spent acid. At higher temperatures, between 150 and $220^{\circ} \mathrm{F}$, a slight increase was noted (Fig. 3.21).

Stimulation fluids can form emulsions with residual oil, that can block the wormholes and cause formation damage. Demulsifiying agents are added to the acid mixture to break or prevent formation of stable oil-water emulsions.

\begin{tabular}{lc}
\hline \multicolumn{1}{c}{ Components } & $\begin{array}{c}\text { Concentration } \\
\text { (wt \%) }\end{array}$ \\
\hline \hline & \\
Isopropanol & $60-70$ \\
Polyoxyalkylenes & $1-5$ \\
Light aromatic naphta & $1-5$ \\
1,2,4-Trimethylbenzene & $1-5$ \\
\hline
\end{tabular}

Table 3.3: Composition of demulsifier tested.

The impact of the demulsifiying agent with the increased temperature was found considerable (Fig. 3.22). Although the apparent viscosity raised initially, a sharp decline was noted at approximately $100^{\circ} \mathrm{F}$, and a lower viscosity trend maintained compared to the spent acid with no demulsifier. High isopropanol content, as seen in the Table 3.3 is concluded to be the cause of this viscosity reduction.

Viscosity of the solutions with demulsifier and $\mathrm{H}_{2} \mathrm{~S}$ scavenger did not show dependency on shear history at room temperature (Fig. 3.23). 


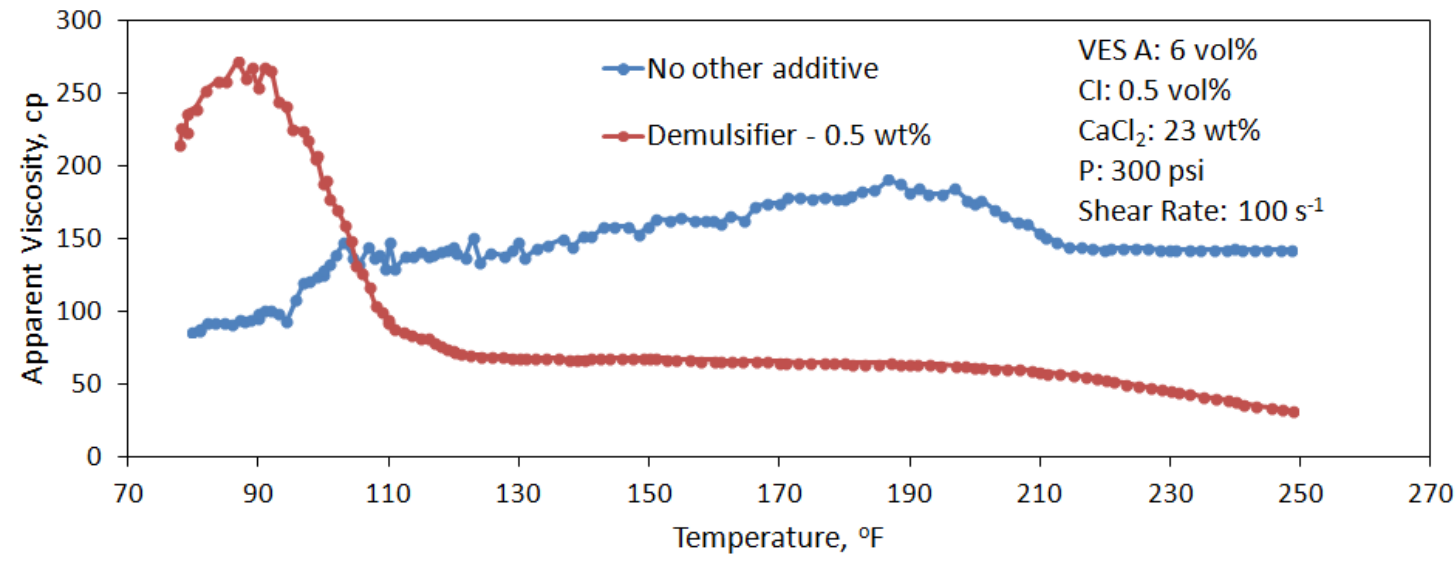

Figure 3.22: Effect of demulsifier on apparent viscosity of spent acid as a function of temperature.

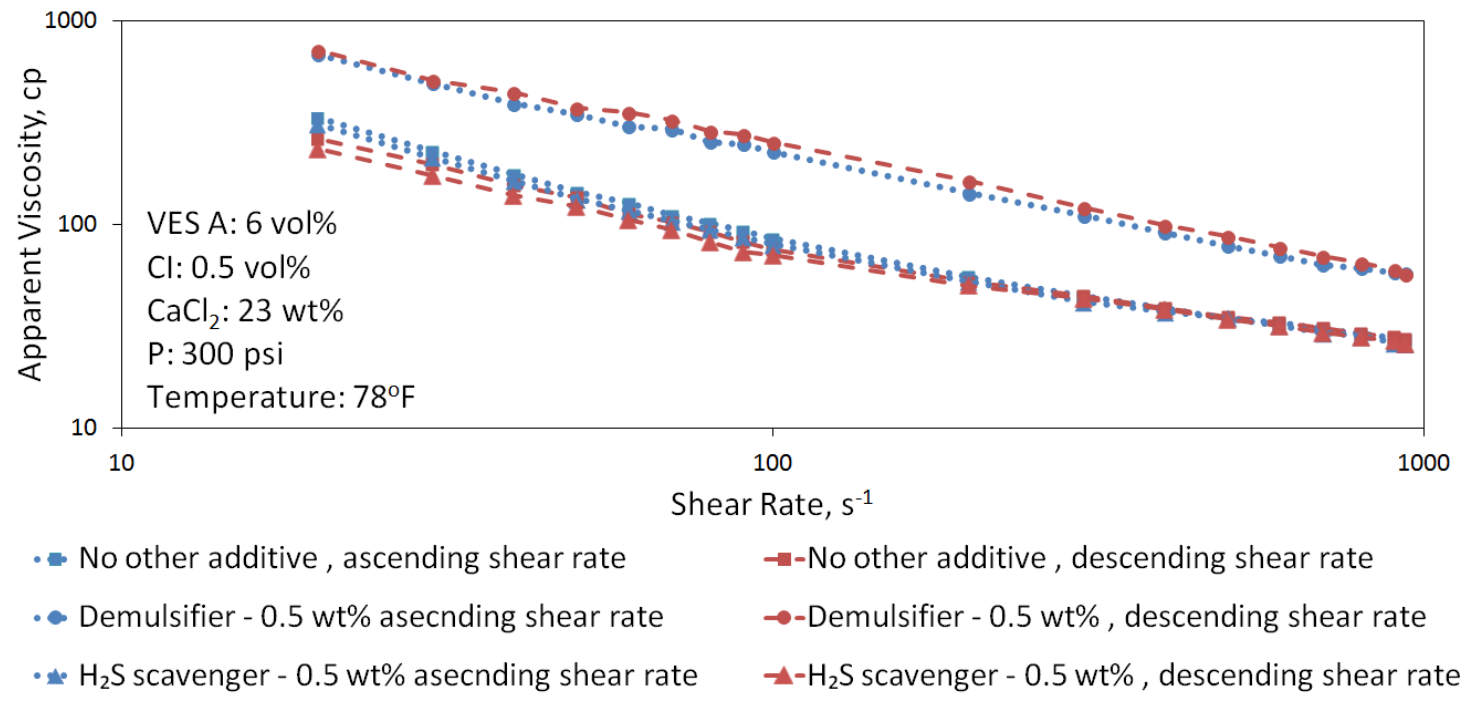

Figure 3.23: Effect of additives on apparent viscosity of spent acid as a function of shear rate. 


\subsubsection{Effect of Iron Contamination}

As explained in the section 3.4.3, $\mathrm{Fe}^{3+}$ and $\mathrm{Cl}^{-}$ions form $\mathrm{FeCl}_{4}^{-}$that interacts with the cationic center $\left(\mathrm{N}^{+}\right)$of the VES molecules. In live acid, this interaction led viscosity increase. In spent acid, however, the interaction was stronger that caused phase separation. Two immiscible fluids can be seen in Fig. 3.24c. Phase separation started at temperature of $120^{\circ} \mathrm{F}$ resulting a sharp decline in the apparent viscosity. As the temperature increased further, apparent viscosity reading close to that of water was observed( Fig. 3.25). Application of high shear rate at room temperature did not cause any phase separation. The fluid mostly gained its viscosity back after shearing was desisted (Fig. 3.26).

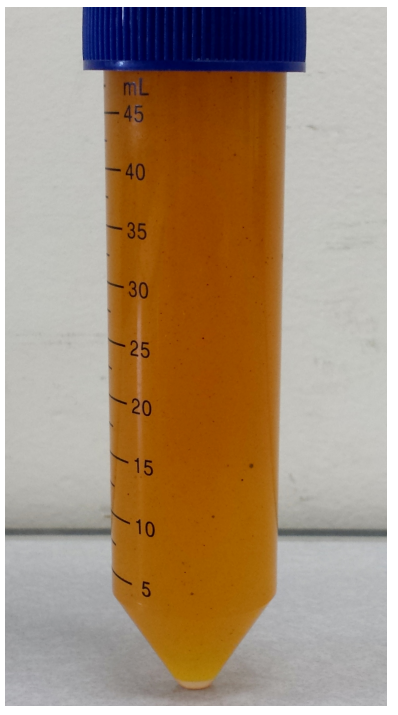

(a) Before the experiment

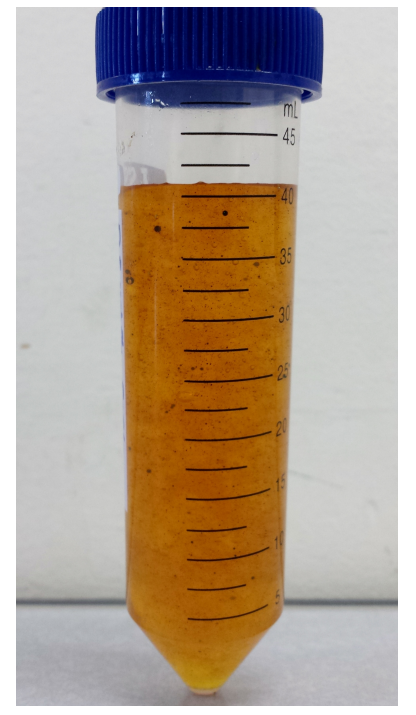

(b) After high shear rate applied

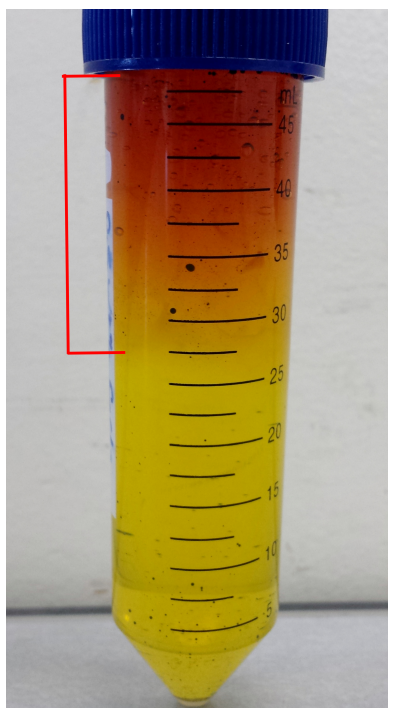

(c) After high temperature applied

Figure 3.24: Spent acid samples with iron contamination. 


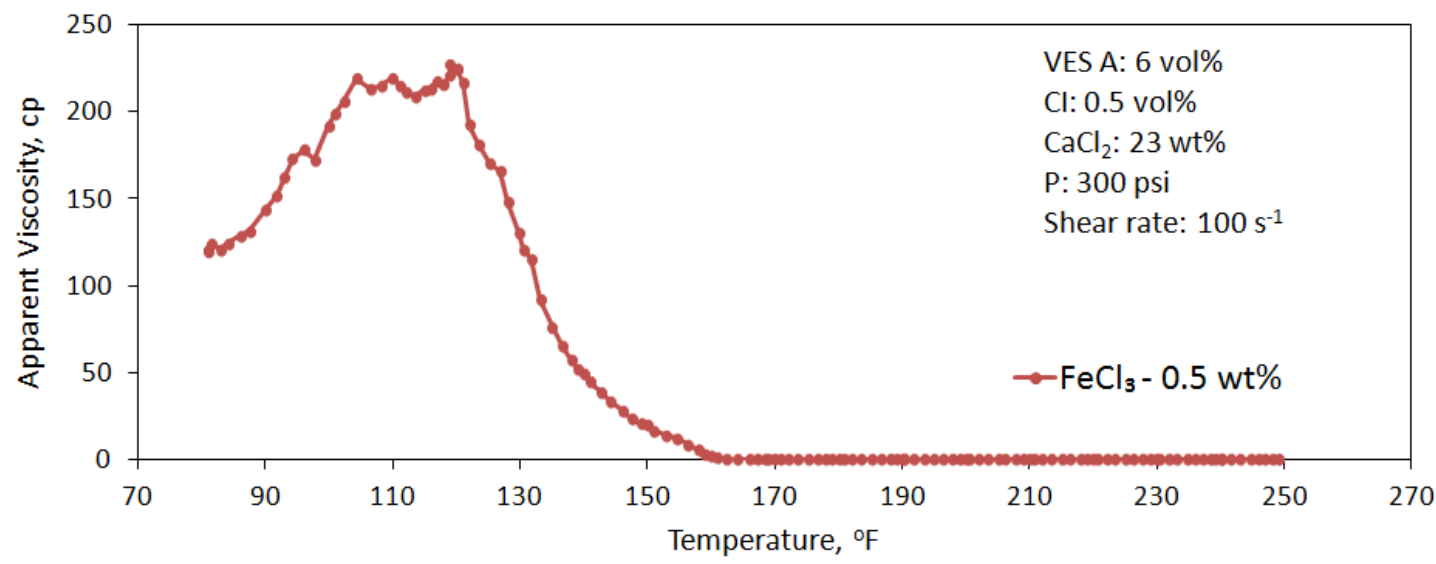

Figure 3.25: Effect of Fe(III) contamination on viscosity of spent acid as a function of temperature.

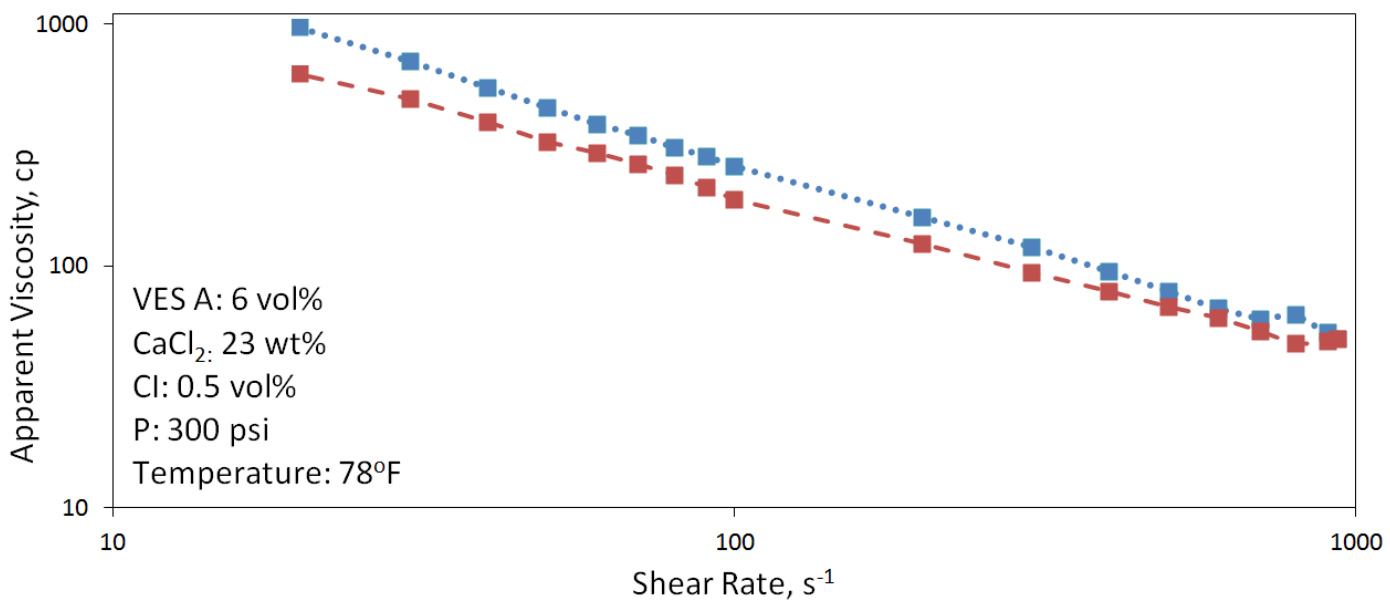

$\mathrm{FeCl}_{3}-0.5 \mathrm{wt} \%$, ascending shear rate $-\mathrm{FeCl}_{3}-0.5 \mathrm{wt} \%$ descending shear rate

Figure 3.26: Effect of $\mathrm{Fe}(\mathrm{III})$ contamination on viscosity of spent acid as a function of shear rate. 


\subsubsection{Effect of Iron Control Agents}

To cope withe the problems associated with iron contamination, iron control agents are used with the stimulation fluid. Citric acid and EDTA (ethylenedinitrilo tetraacedic acid disodium salt) were analyzed. Chemical structures of both chemicals are shown in Fig.3.27 and 3.28.
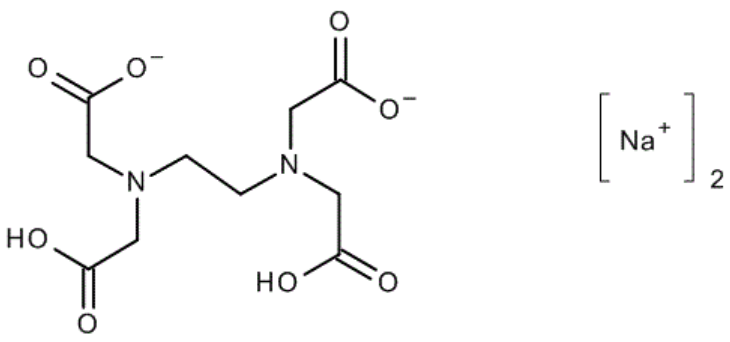

Figure 3.27: Chemical structure of ethylenedinitrilo tetraacedic acid disodium salt.<smiles>O=C(O)CC(O)(CC(=O)O)C(=O)O</smiles>

Figure 3.28: Chemical structure of citric acid.

$0.5 \mathrm{wt} \%$ concentration of agent was added to the spent acid and viscosity measurements were conducted at $100 \mathrm{~s}^{-1}$ shear rate and 300 psi pressure. Fig. 3.29 showes that iron control agents do not have a significant effect on the viscosity of the solution. The graphs for both EDTA and citric acid follows nearly same trend with the spent acid viscosity including no iron control agent. The viscosity of the 
spent acid with EDTA showed an out of the common trend with the ascending shear rate, but the the results were linear with the descending shear rate, as expected. It is concluded that the apparent viscosity is not dependent on the shear history (Fig. $3.30)$.

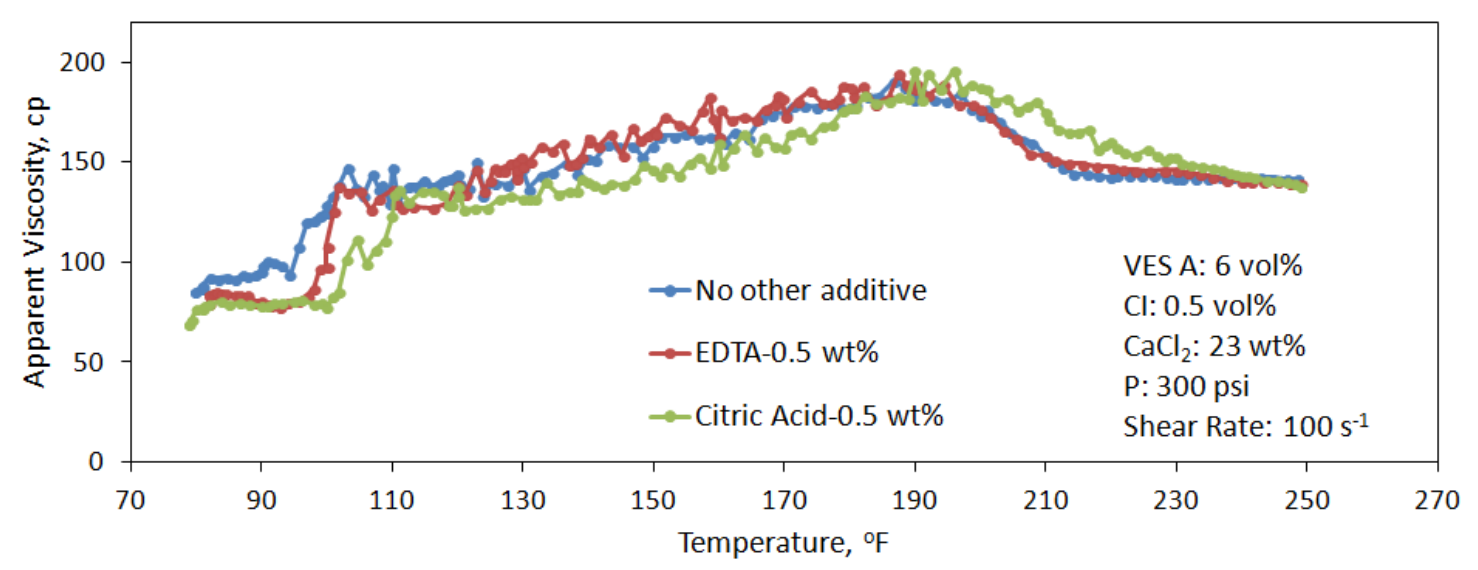

Figure 3.29: Effect of iron control agents on viscosity of spent acid as a function of temperature.

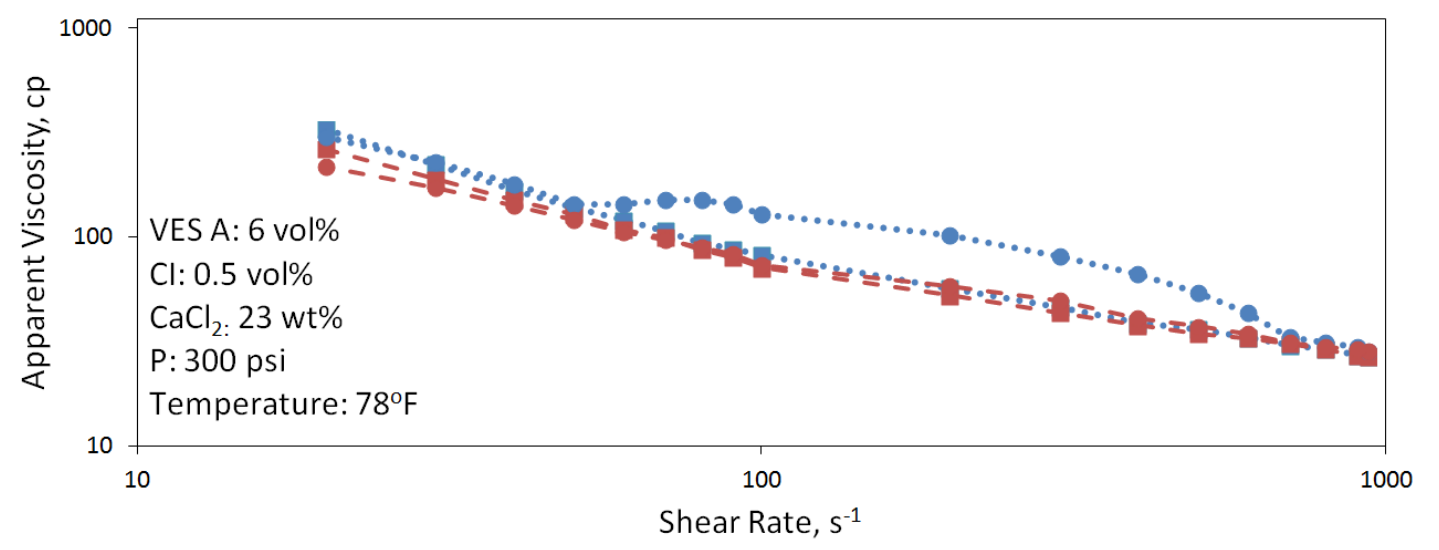

- Citric Acid-0.5 wt\%, ascending shear rate $\quad-$-Citric Acid-0.5 wt\%, descending shear rate

- EDTA-0.5 wt\%, ascending shear rate $\rightarrow$-EDTA-0.5 wt\%, descending shear rate

Figure 3.30: Effect of iron control agents on viscosity of spent acid as a function of shear rate. 


\section{CONCLUSION}

This study examined the viscous behavior of a new class zwitterionic, erucamidopropyl hydroxypropyl sulfobetaine, surfactant that is used as a diverting agent in acid stimulation applications. The effects of acid additives including corrosion inhibitor,, methanol, iron control agents, mutual solvent, $\mathrm{H}_{2} \mathrm{~S}$ scavenger and demulsifer, $\mathrm{Fe}(\mathrm{III})$ contamination, salt type and salt concentration on the apparent viscosity of acid stimulation fluid were investigated. Apparent viscosity of the samples were measured by using a HPHT viscometer. The following conclusions were drawn for the stimulation fluids examined:

1. Surfactant concentration was effective on the rheology. Optimum viscosity trend was obtained with 6 vol\% VES-A concentration.

2. Apparent viscosity values of VES-based live and spent acid systems were found to be dependent on temperature. Simulated VES-based spent acid built up sufficient viscosity for acid diversion at temperatures up to $270^{\circ} \mathrm{F}$.

3. Shear sweep tests were conducted in a range of shear rates of 10 to $935 \mathrm{~s}^{-1}$. Spent acid solutions showed shear thinning behaviors. High rate of shearing did not cause permanent viscosity loss on the spent acid blends.

4. VES-A did not build high viscosity in the live acid, which is preferable for an easier acid injection process. Apparent viscosity of the live acid was dependent on the history of shearing.

5. Concentration of $\mathrm{CaCl}_{2}$ in the solution was an effective factor on the apparent viscosity. The solution including $23 \mathrm{wt} \% \mathrm{CaCl}_{2}$ showed the highest viscosity at high temperatures and a stable trend at all temperatures. 
6. Divalent cations $\left(\mathrm{Ca}^{2+}\right.$ and $\left.\mathrm{Mg}^{2+}\right)$ were more capable of enhancing the viscosity of the spent acid than monovalent cations $\left(\mathrm{Na}^{+}\right.$and $\left.\mathrm{K}^{+}\right)$in temperature range of 120 to $170^{\circ} \mathrm{F}$.

7. Increased corrosion inhibitor concentration decreased the viscosity of both live and spent acids due to high formic acid and isopropanol content.

8. Methanol concentration adversely affected the apparent viscosity.

9. The addition of mutual solvent to the spent acid caused a detrimental loss in the apparent viscosity.

10. Demulsifier caused an initial increase in the apparent viscosity. However, loss in the apparent viscosity was observed at temperatures higher than $100^{\circ} \mathrm{F}$.

11. Fe(III) contamination caused generation of VES-iron complex, which caused phase separation and loss of viscosity in the spent acid.

12. VES-A showed compatibility with the iron control agents $\mathrm{H}_{2} \mathrm{~S}$ scavenger. Citric acid, EDTA and $\mathrm{H}_{2} \mathrm{~S}$ scavenger at concentrations of $0.5 \mathrm{wt} \%$ did not significantly affect the viscosity of spent acid.

The data presented through this study will be helpful to estimate the viscous behavior of this high temperature resistant VES-based acid, which is essential for a successful well treatment. 


\section{REFERENCES}

Al-Muhareb, M.A., Nasr-El-Din, H.A., Samuel, E. et al. 2003. Acid Fracturing of Power Water Injectors: A New Field Application Using Polymer-free Fluids. Presented at the SPE European Formation Damage Conference, The Hague, Netherlands, 13-14 May. SPE-82210-MS.

http://dx.doi.org/10.2118/82210-MS.

Al-Mutawa, M., Al-Anzi, E.H., Jemmali, M. et al. 2005. Zero Damaging Stimulation and Diversion Fluid: Field Cases from the Carbonate Formations in North Kuwait. SPE Production \& Facilities 20 (02): 94-105. SPE-80225-PA. http://dx.doi.org/10.2118/80225-PA.

Al-Nakhli, A.R., Nasr-El-Din, H.A., and Al-Baiyat, I.A. 2008. Interactions of Iron and Viscoelastic Surfactants: A New Formation-Damage Mechanism. Presented at the SPE International Symposium and Exhibition on Formation Damage Control, Lafayette, Louisiana, 13-15 February. SPE-112465-MS.

http://dx.doi.org/10.2118/112465-MS.

Candau, S., Khatory, A., Lequeux, F. et al. 1993. Rheological Behaviour of Wormlike Micelles: Effect of Salt Content. Journal de Physique IV 3 (C1): 197-209. http://dx.doi.org/10.1051/jp4:1993117.

Candau, S. and Zana, R. 1981. Effect of Alcohols on the Properties of Micellar Systems. Journal of Colloid and Interface Science 84 (1): 206-219.

http://dx.doi.org/10.1016/0021-9797(81)90277-0.

Card, R.J., Brown, J.E., Vinod, P.S. et al. 1999. Methods for Limiting the Inflow of Formation Water and for Stimulating Subterranean Formations. US Patent No. $5,979,557$. 
Cates, M.E. and Candau, S.J. 1990. Statics and Dynamics of Worm-Like Surfactant Micelles. Journal Of Physics: Condensed Matter 2 (33): 6869-6892.

http://dx.doi.org/10.1088/0953-8984/2/33/001.

Chang, F.F., Qu, Q., and Frenier, W. 2001. A Novel Self-Diverting-Acid Developed for Matrix Stimulation of Carbonate Reservoirs. Presented at the SPE International Symposium on Oilfield Chemistry, Houston, Texas, 13-16 February. SPE-65033-MS. http://dx.doi.org/10.2118/65033-MS.

Coulter, G.R. and Jennings, A.R., Jr. 1999. A Contemporary Approach to Matrix Acidizing. SPE Production \& Facilities 14 (02): 144-149. SPE-56279-PA. http://dx.doi.org/10.2118/56279-PA.

Crews, J.B. 2005. Internal Phase Breaker Technology For Viscoelastic Surfactant Gelled Fluids. Presented at the SPE International Symposium on Oilfield Chemistry, The Woodlands, Texas, 2-4 February. SPE-93449-MS. http://dx.doi.org/10.2118/93449-MS.

Crowe, C.W., Hutchinson, B.H., and Trittipo, B.L. 1989. Fluid-Loss Control: The Key to Successful Acid Fracturing. SPE Production Engineering 4 (02): 215-220. SPE-16883-PA. http://dx.doi.org/10.2118/16883-PA.

Dahayanake, M.S., Yang, J., Niu, J.H. et al. 2002. Viscoelastic Surfactant Fluids and Related Methods of Use US Patent No. 6482866.

Evani, S. 1984. Water Soluble Polymer, Surfactant, and Salt-Used in Enhanced Oil Recovery. US Patent No. 4,432,881.

Gadberry, J.F., Engel, M.J., Nowak, J.D. et al. 2014. Thickened Viscoelastic Fluids and Uses Thereof. U.S. Patent Application Publication No. 20140076572 A1.

Gallus, J.P. and Pye, D.S. 1972. Fluid Diversion to Improve Well Stimulation. Presented at the Joint AIME-MMIJ Meeting, Tokyo, Japan, 25-27 May. SPE3811-MS. http://dx.doi.org/10.2118/3811-MS. 
Hoffmann, H., Rauscher, A., Gradzielski, M. et al. 1992. Influence of Ionic Surfactants on the Viscoelastic Properties of Zwitterionic Surfactant Solutions. Langmuir 8 (9): 2140-2146. http://dx.doi.org/10.1021/la00045a013.

Holmberg, K., Jonsson, B., Kronberg, B. et al. 2003. Surfactants and Polymers in Aqueous Solution, 2nd edition. Chichester, West Sussex, England; Hoboken, NJ: John Wiley \& Sons Ltd.

Hong, D. and Kuboi, R. 1999. Evaluation of the Alcohol-mediated Interaction Between Micelles Using Percolation Processes of Reverse Micellar Systems. Biochemical Engineering Journal 4 (1): 23-29.

http://dx.doi.org/10.1016/S1369-703X(99)00027-3.

Israelachvili, J.N. 2011. Thermodynamic Principles of Self-Assembly. In Intermolecular and Surface Forces, 3rd edition, Chap. 19, 503-534. San Diego, CA: Academic Press.

Israelachvili, J.N. and Mitchell, D.J. 1975. A model for the Packing of Lipids in Bilayer Membranes. Biochimica et Biophysica Acta (BBA)-Biomembranes 389 (1): 13-19. http://dx.doi.org/10.1016/0005-2736(75)90381-8.

Johnson, D.E., Fox, K.B., Burns, L.D. et al. 1988. Carbonate Production Decline Rates are Reduced Through Improvements in Gelled Acid Technology. Presented at the Permian Basin Oil and Gas Recovery Conference, Midland, Texas, 10-11 March. SPE-17297-MS. http://dx.doi.org/10.2118/17297-MS.

Kalfayan, L. 2008. Production Enhancement with Acid Stimulation, 2nd edition. Tulsa, OK: PennWell.

Lequeux, F. 1996. Structure and Rheology of Wormlike Micelles. Current Opinion in Colloid $\mathcal{E}$ Interface Science 1 (3): 341-344. http://dx.doi.org/10.1016/S1359-0294(96)80130-0. 
Li, L., Nasr-El-Din, H. A., Crews, J. B. et al. 2011. Impact of Organic Acids/Chelating Agents on the Rheological Properties of an Amidoamine-Oxide Surfactant. SPE Production \& Operations 26 (01): 30-40. SPE-128091-PA.

http://dx.doi.org/10.2118/128091-PA.

Lo, K.K. and Dean, R.H. 1989. Modeling of Acid Fracturing. SPE Production Engineering Journal 4 (2): 194-200. SPE-17110-PA. http://dx.doi.org/10.2118/17110-PA.

Lungwitz, B.R., Fredd, C.N., Brady, M.E. et al. 2007. Diversion and Cleanup Studies of Viscoelastic Surfactant-Based Self-Diverting Acid. SPE Production $\mathcal{E}$ Operations 22 (01): 121-127. SPE-86504-PA.

http://dx.doi.org/10.2118/86504-PA.

Lynn, J.D. and Nasr-El-Din, H.A. 2001. A Core Based Comparison Of The Reaction Characteristics Of Emulsified And In-Situ Gelled Acids In Low Permeability, High Temperature, Gas Bearing Carbonates. Presented at the SPE International Symposium on Oilfield Chemistry, Houston, Texas, 13-16 February. SPE-65386MS. http://dx.doi.org/10.2118/65386-MS.

Nasr-El-Din, H.A., Al-Driweesh, S., Al-Muntasheri, G.A. et al. 2003. Acid Fracturing HT/HP Gas Wells Using a Novel Surfactant Based Fluid System. Presented at the SPE Annual Technical Conference and Exhibition, Denver, Colorado, 5-8 October. SPE-84516-MS. http://dx.doi.org/10.2118/84516-MS.

Nasr-El-Din, H.A., Al-Humaidan, A.Y., Fadhel, B.A. et al. 2002. Investigation of Sulfide Scavengers in Well-Acidizing Fluids. SPE Production $\&$ Facilities 17 (04): 229-235. SPE-80289-PA. http://dx.doi.org/10.2118/80289-PA.

Nasr-El-Din, H.A., Alhabib, N.S., Al-Mumen, A.A. et al. 2006. A New Effective Stimulation Treatment for Long Horizontal Wells Drilled in Carbonate Reservoirs. SPE Production 83 Operations 21 (03): 330-338. SPE-86516-PA. http://dx.doi.org/10.2118/86516-PA. 
Nelson, E.B., Lungwitz, B., Dismuke, K. et al. 2005. Viscosity Reduction of Viscoelastic Surfactant Based Fluids. U.S. Patent Application Publication No. 20020193257 A1.

Nierode, D.E., Williams, B.R., and Bombardieri, C.C. 1972. Prediction of Stimulation From Acid Fracturing Treatments. Journal of Canadian Petroleum Technology 11 (04): PETSOC-72-04-04. http://dx.doi.org/10.2118/72-04-04.

Porter, M.R. 1991. Handbook of Surfactants, 1st edition. Boston, MA: Springer US.

Renpu, W. 2011. Measures for Putting a Well into Production. In Advanced Well Completion Engineering, 3rd edition, Chap. 8, 423-480. Waltham, MA: Gulf Professional Pub.

Samuel, M., Card, R.J., Nelson, E.B. et al. 1997. Polymer-Free Fluid for Hydraulic Fracturing. Presented at the SPE Annual Technical Conference and Exhibition, San Antonio, Texas, 5-8 October. SPE-38622-MS.

http://dx.doi.org/10.2118/38622-MS.

Shu, Y., Wang, G., Nasr-El-Din, H.A. et al. 2015. Interactions of Fe(III) and Viscoelastic- Surfactant-Based Acids. SPE Production 8 Operations. SPE165149-PA (in press; posted August 2015). http://dx.doi.org/10.2118/165149-PA.

Taylor, D., Kumar, P. S., Fu, D. et al. 2003. Viscoelastic Surfactant Based SelfDiverting Acid for Enhanced Stimulation in Carbonate Reservoirs. Presented at the SPE European Formation Damage Conference, The Hague, Netherlands, 13-14 May. SPE-82263-MS. http://dx.doi.org/10.2118/82263-MS.

Taylor, K. C. and Nasr-El-Din, H. A. 2002. Coreflood Evaluation of In-Situ Gelled Acids. Presented at the International Symposium and Exhibition on Formation Damage Control, Lafayette, Louisiana, 20-21 February. SPE-73707-MS. http://dx.doi.org/10.2118/73707-MS. 
Taylor, K.C., Nasr-El-Din, H.A., and Al-Alawi, M.J. 1999. Systematic Study of Iron Control Chemicals Used During Well Stimulation. SPE Journal 4 (01): 19-24. SPE-54602-PA. http://dx.doi.org/10.2118/54602-PA.

Yeager, V. and Shuchart, C. 1997. In Situ Gels Improve Formation Acidizing. Oil and Gas Journal 95 (3): 70-72. OSTI ID: 423114.

Zana, R. 1984. Effect of medium chain-length alcohols on the micelles of tetradecyltrimethylammonium bromide. Journal of Colloid and Interface Science 101 (2): 587-590. http://dx.doi.org/10.1016/0021-9797(84)90073-0.

Zana, R. and Kaler, E.W. 2007. Giant Micelles: Properties and Applications. 1st edition. Boca Raton: CRC Press. 